\title{
M3 Muscarinic Acetylcholine Receptor Expression Confers Differential Cholinergic Modulation to Neurochemically Distinct Hippocampal Basket Cell Subtypes
}

\author{
Christian A. Cea-del Rio, ${ }^{1 \star}$ J. Josh Lawrence, ${ }^{1,2 \star}$ Ludovic Tricoire, ${ }^{1}$ Ferenc Erdelyi, ${ }^{3}$ Gabor Szabo, ${ }^{3}$ and Chris J. McBain ${ }^{1}$ \\ ${ }^{1}$ Program in Developmental Neurobiology, Eunice Kennedy Shriver National Institute of Child Health and Human Development, Bethesda, Maryland \\ 20892, ${ }^{2}$ Center for Structural and Functional Neuroscience, Department of Biomedical and Pharmaceutical Sciences, The University of Montana, Missoula, \\ Montana 59812, and ${ }^{3}$ Laboratory of Molecular Biology and Genetics, Institute of Experimental Medicine, Hungarian Academy of Sciences, H-1450 \\ Budapest, Hungary
}

Cholinergic neuromodulation of hippocampal circuitry promotes network oscillations and facilitates learning and memory through cellular actions on both excitatory and inhibitory circuits. Despite widespread recognition that neurochemical content discriminates between functionally distinct interneuron populations, there has been no systematic examination of whether neurochemically distinct interneuron classes undergo differential cholinergic neuromodulation in the hippocampus. Using GFP transgenic mice that enable the visualization of perisomatically targeting parvalbumin-positive $(\mathrm{PV}+)$ or cholecystokinin-positive $(\mathrm{CCK}+)$ basket cells $(\mathrm{BCs})$, we tested the hypothesis that neurochemically distinct interneuron populations are differentially engaged by muscarinic acetylcholine receptor (mAChR) activation. Cholinergic fiber activation revealed that CCK BCs were more sensitive to synaptic release of ACh than PV BCs. In response to depolarizing current steps, $\mathrm{mAChR}$ activation of $\mathrm{PV} \mathrm{BCs}$ and $\mathrm{CCK} \mathrm{BCs}$ also elicited distinct cholinergic response profiles, differing in $\mathrm{mAChR}$-induced changes in action potential (AP) waveform, firing frequency, and intrinsic excitability. In contrast to PV BCs, CCK BCs exhibited a mAChR-induced afterdepolarization (mADP) that was frequency and activity-dependent. Pharmacological, molecular, and loss-of-function data converged on the presence of M3 mAChRs in distinguishing CCK BCs from PV BCs. Firing frequency of CCK BCs was controlled through M3 mAChRs but PV BC excitability was altered solely through M1 mAChRs. Finally, upon mAChR activation, glutamatergic transmission enhanced cellular excitability preferentially in CCK BCs but not in PV BCs. Our findings demonstrate that cell type-specific cholinergic specializations are present on neurochemically distinct interneuron subtypes in the hippocampus, revealing an organizing principle that cholinergic neuromodulation depends critically on neurochemical identity.

\section{Introduction}

Basket cells are a major class of GABAergic interneuron providing perisomatic inhibition to hundreds of pyramidal cells (PCs) simultaneously, synchronizing cell ensembles during theta (4-12 $\mathrm{Hz})$ and gamma $(30-80 \mathrm{~Hz})$ oscillations (Bartos et al., 2007). In the hippocampus, two neurochemically distinct BC subtypes are present, cholecystokinin (CCK)- and parvalbumin (PV)containing BC populations (Freund and Katona, 2007). CCK $\mathrm{BCs}$ and PV BCs have distinct passive, active, and synaptic prop-

Received 0ct. 9, 2009; revised Nov. 20, 2009; accepted March 9, 2010.

National Institute of Child Health and Human Development (NICHD) intramural funding (C.MC.B.) and National Institutes of Health Grant P20RR015583 from the Centers of Biomedical Research Excellence Program of the National Center for Research Resources (J.L.) supported this work. We are grateful to Drs. Bruno Cauli for primers, Z. Josh Huang for line B13 PV-GFP mice, Jurgen Wess for all muscarinic acetylcholine receptor knock-out mice, and Vincent Schram and the NICHD Microscopy and Imaging Core for assisting in the acquisition of tiled three-dimensional confocal images of biocytin-labeled cells. We also thank Brian Jeffries for immunocytochemistry and biocytin labeling, David Bonislawski for confocal imaging and immunocytochemistry, and members of the McBain and Lawrence laboratories for helpful comments on the manuscript.

*C.A.C.-d.R. and J.J.L. contributed equally to the work.

Correspondence should be addressed to Dr. J. Josh Lawrence, Center for Structural and Functional Neuroscience, Department of Biomedical and Pharmaceutical Sciences, 391 Skaggs Building, The University of Montana, Missoula, MT 59812. E-mail: josh.lawrence@umontana.edu.

DOI:10.1523/JNEUROSCI.5040-09.2010

Copyright $\odot 2010$ the authors $\quad 0270-6474 / 10 / 306011-14 \$ 15.00 / 0$ erties (Hefft and Jonas, 2005; Glickfeld and Scanziani, 2006; Daw et al., 2009), are integrated differently into glutamatergic networks (Gulyás et al., 1999; Glickfeld and Scanziani, 2006), and exhibit differences in firing patterns during theta oscillations in vivo (Klausberger et al., 2005). Together, these observations imply that CCK BC and PV BC subtypes are differentially engaged during hippocampal-dependent behavioral tasks (Glickfeld and Scanziani, 2006; Freund and Katona, 2007), encoding distinct aspects of sensory experience.

A number of neuromodulatory systems feed into the hippocampus, conveying information about the saliency and emotional context of sensory information that is being processed. One such neuromodulator, acetylcholine, is synaptically released into the hippocampus from cholinergic neurons originating in the medial septum-diagonal band of Broca (MS-DBB) (Cobb and Davies, 2005), thereby facilitating learning and memory (Huerta and Lisman, 1993; Hasselmo, 2006) through cholinergic induction of neural oscillations (Lee et al., 1994; Fisahn et al., 1998, 2002). Perisomatic inhibition is active during carbacholinduced oscillations (Mann et al., 2005), raising the possibility that perisomatic release of GABA may be controlled not only through synaptic excitation of glutamatergic networks but also 
by cholinergic receptors present on BCs themselves (McQuiston and Madison, 1999a,b; Widmer et al., 2006). Despite immunocytochemical evidence that cholinergic receptor expression differs between PV and CCK interneuron populations (Freedman et al., 1993; Hájos et al., 1998; Freund and Katona, 2007; Morales et al., 2008) and numerous functional studies examining cholinergic neuromodulation of morphologically defined CA1 hippocampal interneurons (Parra et al., 1998; McQuiston and Madison, 1999a,b; Lawrence et al., 2006a; Widmer et al., 2006), a systematic examination the cellular consequences of cholinergic neuromodulation of hippocampal BCs has been hampered by uncertainty in neurochemical identity.

In this study, we performed whole-cell recordings in hippocampal slices from PV-GFP or GAD65-GFP transgenic mice. In these mice, GFP is expressed in neurochemically restricted interneuron populations, facilitating the systematic examination of PV BC and CCK BC subtypes, respectively. We find that PV $\mathrm{BCs}$ and CCK BCs are differentially sensitive to synaptic release of acetylcholine, are differentially tuned to elicit distinct response profiles to $\mathrm{mAChR}$ activation, and express different postsynaptic mAChR subtypes. These observations demonstrate that cholinergic modulation of hippocampal basket cell targets is cell type specific. The differential engagement of neurochemically distinct hippocampal interneuron subtypes appears to be a shared principle between hippocampal and neocortical interneurons.

\section{Materials and Methods}

Slice preparation and solutions. All experiments were conducted in accordance with animal protocols approved by the National Institutes of Health. Fifteen- to 20-d-old PV-GFP (Ango et al., 2008; Goldberg et al., 2008) or GAD65-GFP (López-Bendito et al., 2004) mice were anesthetized by isoflurane inhalation and decapitated. The brain was quickly removed and placed in ice-cold artificial CSF (ACSF) containing (mM): $87 \mathrm{NaCl}, 65$ sucrose, $2.5 \mathrm{KCl}, 1.25 \mathrm{NaH}_{2} \mathrm{PO}_{4}, 25 \mathrm{NaHCO}_{3}, 7 \mathrm{MgCl}_{2}, 0.5$ $\mathrm{CaCl}_{2}$ and 25 glucose (equilibrated with $95 \% \mathrm{O}_{2}$ and $5 \% \mathrm{CO}_{2}, \mathrm{pH} 7.4$ ). Transverse acute hippocampal slices (300 $\mu \mathrm{m}$ thickness) were prepared using a Vibratome 3000 deluxe (Vibratome Company). Hippocampal slices were placed in an incubation chamber at $36^{\circ} \mathrm{C}$ for at least $30 \mathrm{~min}$ before being placed in a submerged bath chamber at $30-36^{\circ} \mathrm{C}$, continuously superfused at $1-2 \mathrm{ml} \mathrm{min}^{-1}$ under carbogen pressure for recordings. The extracellular solution (ECS) contained in mM: $130 \mathrm{NaCl}, 3.5 \mathrm{KCl}, 1.25 \mathrm{NaH}_{2} \mathrm{PO}_{4}, 25$ $\mathrm{NaHCO}_{3}, 2 \mathrm{MgCl}_{2}, 2 \mathrm{CaCl}_{2}$ and 10 glucose saturated with $95 \% \mathrm{O}_{2}$ and $5 \%$ $\mathrm{CO}_{2}$. The ECS also contained $100 \mu \mathrm{M}$ DL-APV (Tocris Bioscience), $25 \mu \mathrm{M}$ DNQX (Sigma), and $5 \mu \mathrm{m}$ gabazine (Sigma), to block NMDA, AMPA/kainate, and $\mathrm{GABA}_{\mathrm{A}}$ receptors, respectively. For glutamatergic synaptic stimulation experiments, APV and DNQX were omitted.

Electrophysiology. GFP-labeled inhibitory interneurons in CA1 were visually identified using differential interference contrast (DIC) and fluorescence videomicroscopy on an Olympus BX51WI or Zeiss FS2 upright microscope (Infrapatch; Luigs and Neumann). Whole-cell current-clamp data were recorded with a Multiclamp 700A amplifier (Molecular Devices Corp.), using recording pipettes (3-5 M $\Omega$ ) pulled on a P97 horizontal puller (Sutter Instruments) or PC10 Narishige vertical puller, and filled with intracellular solution containing the following (in $\mathrm{mm}$ ): 135 potassium gluconate, $20 \mathrm{KCl}, 10$ HEPES, 0.1 EGTA, 2 MgATP, $0.3 \mathrm{Na}_{2} \mathrm{GTP}$. Recordings were low-pass filtered at $4 \mathrm{kHz}$ (Bessel filter) and digitized at $10 \mathrm{kHz}$ (Digidata 1322A) using pClamp 9.2 software (Molecular Devices Corp.). In most experiments, membrane potential and bias current were monitored through two analog channels. Bridge balance was used throughout the current-clamp experiments. After a 1-3 min baseline in control conditions, muscarine $(10 \mu \mathrm{M})$ was added to the bath solution.

Data analysis. Electrophysiological data were analyzed using Axograph $\mathrm{X}$ software on a PC or Mac. In CCK BCs, 1-s-long hyperpolarizing current steps exhibit larger peak than steady-state voltage deflection, likely indicating the presence of the hyperpolarization activated current $I_{\mathrm{h}}$ (Fig. $1 D)$. Therefore, input resistance $\left(R_{\mathrm{m}}\right)$ for each cell was calculated from the peak of the voltage deflection in response to a 1-slong current step $(-30 \mathrm{pA})$. Action potential (AP) spike times were detected at a threshold of $5 \mathrm{mV} / \mathrm{ms}$ using the Event Detection Plug-In Program in Axograph X. The adaptation coefficient was calculated using the first interspike interval (ISI) divided by the average of the last two ISIs of the AP train during the current step. The term afterdeflection (ADF) refers to the difference between the membrane potential immediately after the current injection and the baseline potential before the current step. The ADF can be negative (i.e., afterhyperpolarization or AHP) or positive (i.e., afterdepolarization or ADP). To calculate ADF, membrane potential was averaged over an $100 \mathrm{~ms}$ window commencing $200 \mathrm{~ms}$ (whole-cell experiments) or $500 \mathrm{~ms}$ (synaptic stimulation experiments) after the end of the current injection. The baseline potential was measured over the $100 \mathrm{~ms}$ preceding the onset of the current injection. AP discharge frequency refers to the mean frequency during the current stimulation. The integral curves were calculated from each ADF response using the "integration" function of Axograph X. Finally, average values in the text and figures are expressed as Mean \pm SEM. We used paired and unpaired Student's $t$ tests for statistical comparisons unless otherwise stated.

Animals. mAChR knock-out (KO) mice (Wess et al., 2007) were received from Taconic with permission of the owner Dr. Jurgen Wess [National Institute of Diabetes and Digestive and Kidney Diseases (NIDDK), National Institutes of Health]. Transgenic "line B13" PV-GFP (Ango et al., 2008; Goldberg et al., 2008) and GAD65-GFP mice were crossed with different $\mathrm{mAChR}$ KO animals (Dr. Jurgen Wess, NIDDK) to obtain GFP-labeled interneurons in the M1, M2, M3, and M1/M3 $\mathrm{mAChR}$ KO background. The animals obtained from these crosses were tested through genotyping protocols (tail snips; see supplemental material, available at www.jneurosci.org, for genotyping sequences). Only homozygous KO GFP+ animals were used in this study.

Extracellular stimulation of cholinergic afferents. Similar to Cobb and colleagues (Widmer et al., 2006), bipolar stimulating electrodes were fabricated from twisted Formvar insulated nickel/chromium wire (26 $\mu \mathrm{m}$ diameter, A-M Systems, Inc.). Stimulation electrodes connected to an A360 stimulation isolator (World Precision Instruments) were placed in the CA1 stratum oriens (SO); stimuli consisted of trains of five squarewave pulses (100-600 $\mu \mathrm{A}$ fixed current intensity, $200 \mu$ s duration) at 20 $\mathrm{Hz}$ delivered every $5 \mathrm{~min}$. The metabotropic glutamate receptor antagonist MCPG $(500 \mu \mathrm{M})$, the $\mathrm{GABA}_{\mathrm{B}}$ antagonist CGP55845 (1 $\mu \mathrm{M}$; Tocris Bioscience) and the cholinesterase inhibitor tacrine hydrochloride (20 $\mu \mathrm{M}$; Tocris Bioscience) were added to the ECS as described in the text.

Extracellular stimulation of Shaeffer collateral afferents. For Shaeffer collateral (SC) stimulation experiments, a cut was made between the CA3 and $\mathrm{CA} 1$ areas to reduce contamination by spontaneous glutamatergic synaptic events evoked by muscarine in CA3. A bipolar stimulation electrode (as above) was placed in CA1 stratum radiatum (SR). The protocols consisted of a single pulse or a train of five square-wave pulses at $20 \mathrm{~Hz}$ (30-90 $\mu \mathrm{A}$ fixed current intensity, $100 \mu$ s duration). In most experiments, the protocols were delivered every $10 \mathrm{~s}$ in alternation.

Single-cell reverse transcription-PCR. After no more than $10 \mathrm{~min}$ of whole-cell recording, we harvested the cytoplasm via aspiration into the recording pipette. The recording pipette was then withdrawn to form an outside-out patch, and the entire pipette solution expelled into a test tube (final volume of $\sim 10 \mu \mathrm{l}$ ). To allow for diffusion of biocytin to distal regions, the slice was perfused for an additional $20 \mathrm{~min}$ after the pipette was withdrawn. Reverse transcription (RT) was performed as previously described (Lambolez et al., 1992). Two steps of multiplex PCR were performed as previously described (Cauli et al., 1997; Tricoire et al., 2010). The cDNAs present in the RT reaction were first amplified simultaneously using all the primer pairs (for each primer pair, the sense and antisense primers were positioned on 2 different exons). A second round of PCR was performed using the first PCR product as template. In this second round, each cDNA was individually amplified using its specific primer pair: glutamic acid decarboxylase 65 and 67 isoforms (GAD67, GAD65), calretinin (CR), PV, calbindin (CB), somatostatin (SOM), neuropeptide Y (NPY), vasoactive intestinal peptide (VIP), and cholecystokinin (CCK). Primers for the vesicular glutamate transporter 1 (vGlut1) and the somatostatin intronic region (SSint) were included as controls for pyramidal cell and genomic DNA contamination, respectively (see Table 1 for primer sequences). BCs 

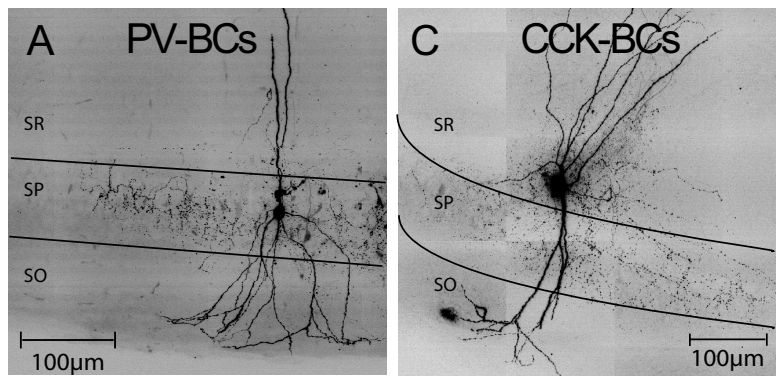

B
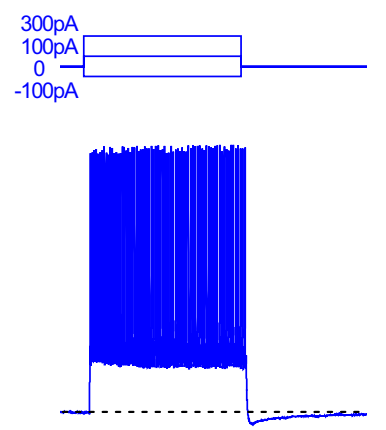

$\mathrm{D}$
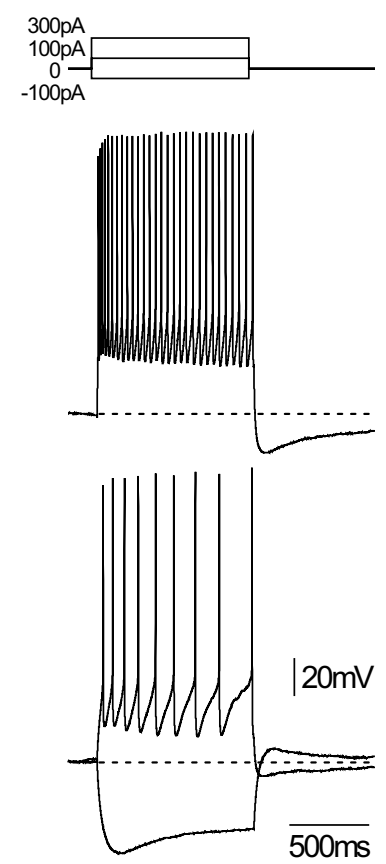

$\mathrm{E}$

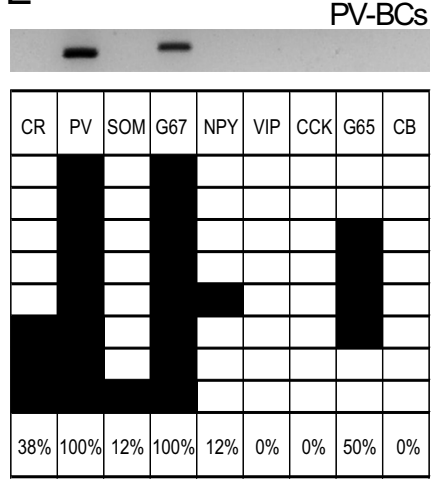

$\mathrm{F}$

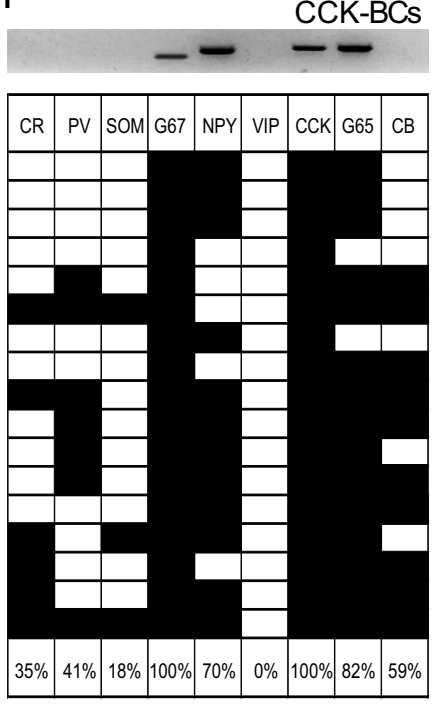

G
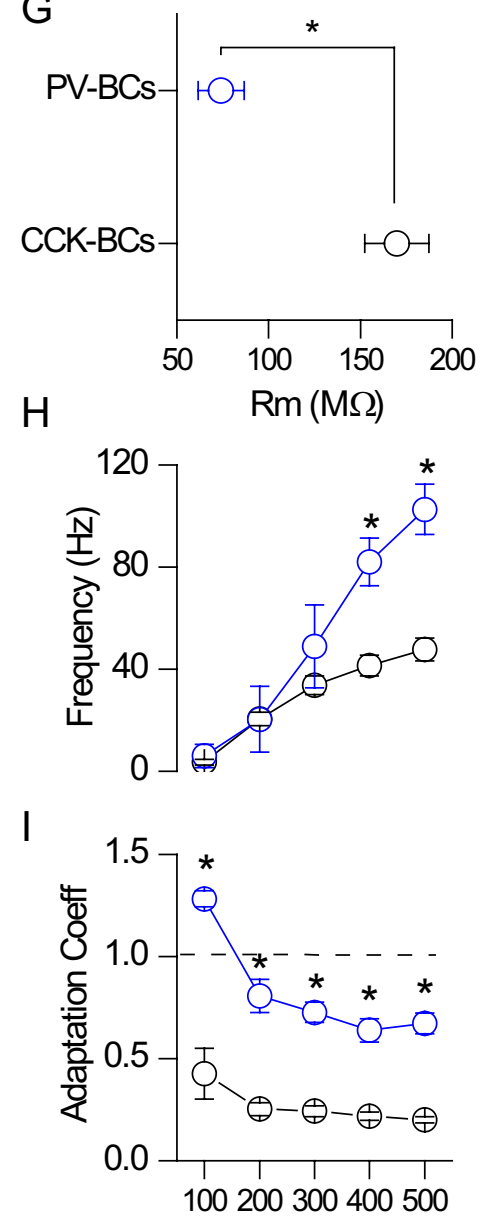

Current injection $(\mathrm{pA})$

Figure 1. Electrophysiological and neurochemical differences between PV BCs and CCK BCS. A, A two-dimensional (2D) flat projection from a tiled three-dimensional confocal image stack of streptavidin-Alexa 555 directed against intracellularly labeled biocytin, converted to grayscale. The PV-GFP cell was morphologically identified as a BC, as indicated by localization of the cell body in SP, vertically oriented dendrites, and axonal arborization in SP. $\boldsymbol{B}$, Voltage responses of the cell in $\boldsymbol{A}$ to $1-\mathrm{s}-$ long, $+300,+100$, and $-100 \mathrm{pA} \mathrm{steps.} \mathrm{The} \mathrm{cell} \mathrm{exhibits} \mathrm{a} \mathrm{"fast} \mathrm{spiking"} \mathrm{phenotype} \mathrm{(blue}$ traces). C, 2D flat projection as in A indicating a morphologically identified CCK BC. The soma was in superficial SR and arborized predominantly in SP. D, Voltage responses of the cell in C to 1-s-long, +300, +100 , and $-100 \mathrm{pA} \mathrm{steps,} \mathrm{indicating} \mathrm{a} \mathrm{strongly} \mathrm{accommodating,} \mathrm{"regular} \mathrm{spiking"} \mathrm{phenotype} \mathrm{(black} \mathrm{traces).} \mathrm{Dotted} \mathrm{lines} \mathrm{in} \boldsymbol{B}$ and $\boldsymbol{D}$ indicate a potential of $-60 \mathrm{mV} . \boldsymbol{E}, \boldsymbol{F}$, Neurochemical profiles of representative subgroups of $\mathrm{PV} \mathrm{BCS}(n=8)(\boldsymbol{E})$ and CCK BCS $(n=17)(\boldsymbol{F})$. The representative cells in $\boldsymbol{A}$ and $\boldsymbol{B}$ and in $\boldsymbol{C}$ and $\boldsymbol{D}$ correspond to the representative scPCR bands in $\boldsymbol{E}$ and $\boldsymbol{F}$, respectively. $G$, Mean input resistance, as measured from the peak voltage deflection to a 1-s-long, $-30 \mathrm{pA}$ current step from $-60 \mathrm{mV}$. $\boldsymbol{H}$, Relationship between current step and firing frequency for CCK BCs and PV BCS. I, Adaptation coefficient, defined by first ISI divided by the average of the last two ISIs. Blue symbols in G-I denote PV BCs; black symbols denote CCK BCS.

that were positive for vGlut1 or SSint were not considered in this study. In a subset of cells, M1-M5 receptor mRNAs were also probed. Each individual PCR was run on a $2 \%$ agarose gel using phix174 digested by HaeIII as a molecular weight marker and stained with ethidium bromide.

Morphological identification. Biocytin (0.2-0.4\%) was included in the recording pipette for post hoc morphological identification of each recorded cell. After whole-cell recording, hippocampal slices were fixed overnight at $4^{\circ} \mathrm{C}$ in $\mathrm{PBS}$ containing $4 \%$ paraformaldehyde (PFA), transferred to PBS, and kept for up to 2 weeks at $4^{\circ} \mathrm{C}$. After permeabilization with $0.3 \%$ Triton X-100 in PBS for $2 \mathrm{~h}$ at room temperature, slices were incubated overnight at $4^{\circ} \mathrm{C}$ with Alexa 555-conjugated streptavidin (final concentration $2 \mu \mathrm{g} / \mathrm{ml}$; Invitrogen) in PBS. Sections were then cryopreserved in PBS containing 25\% sucrose/10\%glycerol and resectioned at $70 \mu \mathrm{m}$ thickness on a freezing microtome. After mounting on gelatincoated slides in Mowiol, sections were imaged with a Zeiss Live DuoScan confocal microscope with a $63 \times$ objective. For each cell, an tiled array of $5 \times 5$ or $7 \times 7$ confocal stacks $(0.5-1.0 \mu \mathrm{m} z$ increment, $40-60 \mu \mathrm{m}$ total depth) were obtained using the Multitime module of the Zeiss LSM software and "stitched" together automatically at the completion of acquisition (total $x-y$ size $\sim 150 \mu \mathrm{m}$ ). Confocal images of interneurons were flat projected, converted to grayscale and color inverted, autoleveled, and cropped in PhotoShop 9.0 for display.

Vesicular acetylcholine transporter immunocytochemistry. For vesicular acetylcholine transporter (vAChT)/GAD65-GFP labeling (Fig. 2A), GAD65-GFP mice were perfused with cold PBS and 4\% PFA, postfixed for 1-3 h, and cryoprotected with $30 \%$ sucrose overnight. The following day, $30 \mu \mathrm{M}$ thick coronal sections were cut using a freezing microtome and stored, rinsed, and permeabilized as above. The tissue was then blocked for $60 \mathrm{~min}$ in 10\% donkey serum and placed in goat anti-vAChT (1:1000; Millipore Bioscience Research Reagents) overnight at $4^{\circ} \mathrm{C}$ (Cobb et al., 1999). Sections were then washed $3 \times 15$ min in PBS and placed in donkey anti-goat Alexa 568 for $60 \mathrm{~min}$. vAChT/GAD65-GFP signals were imaged with a Zeiss Live DuoScan confocal microscope with a $63 \times$ objective. For the vAChT/PV labeling (Fig. $2 \mathrm{~B}$ ), brain tissue from wild-type mice was intracardially perfused with cold PBS and 4\% paraformaldehyde (PFA) and postfixed overnight. The following day, $50 \mu \mathrm{m}$ thick coronal sections were cut using a Leica VT1000S vibratome. Sections were collected and stored in a sucrose-based cryoprotectant at $-20^{\circ} \mathrm{C}$. Sections were rinsed $3 \times 15$ min in PBS and placed in $0.3 \%$ Triton-X for $30 \mathrm{~min}$. The tissue was then blocked for $60 \mathrm{~min}$ in $10 \%$ goat serum and $1 \%$ bovine serum 
Table 1. PCR primers for single-cell RT-PCR

\begin{tabular}{|c|c|c|c|c|c|}
\hline Marker & GenBank number & First $P C R$ primers & Size & Second $\mathrm{PCR}$ primers & $\begin{array}{c}\text { Size } \\
\end{array}$ \\
\hline \multirow[t]{2}{*}{ CB } & \multirow[t]{2}{*}{ NM_009788.4 } & Sense, 139: CGAAAGAAGGCTGGATTGGAG & \multirow[t]{2}{*}{426} & Sense, 194: ATGGACAGAGAGATGATGGAAAAA & \multirow[t]{2}{*}{295} \\
\hline & & Antisense, 544: CCCACACATTTTGATTCCCTG* & & Antisense, 467: TCCAGCTTTCCGTCATTATTTG & \\
\hline \multirow[t]{2}{*}{ CCK } & \multirow[t]{2}{*}{ NM_031161.2 } & Sense, 16: TGTCTGTGCGTGGTGATGGC* & \multirow[t]{2}{*}{554} & Sense, 192: ATACATCCAGCAGGTCCGCAA & \multirow[t]{2}{*}{237} \\
\hline & & Antisense, 546: GCATAGCAACATTAGGTCTGGGAG* & & Antisense, 408: CAGACATTAGAGGCGAGGGGT & \\
\hline \multirow[t]{2}{*}{$C R$} & \multirow[t]{2}{*}{ NM_007586.1 } & Sense, 63: TTGATGCTGACGGAAATGGGTA* & \multirow[t]{2}{*}{265} & Sense, 141: GCTGGAGAAGGCAAGGAAGG & \multirow[t]{2}{*}{151} \\
\hline & & Antisense, 327: CAAGCCTCCATAAACTCAGCG* & & Antisense, 271: ATTCTCTTCGGTCGGCAGGAT & \\
\hline \multirow[t]{2}{*}{ GAD65 } & \multirow[t]{2}{*}{ NM_008078.2 } & Sense, 99: CCAAAAGTTCACGGGCGG* & \multirow[t]{2}{*}{375} & Sense, 219: СACCTGCGACCAAAAACCCT & \multirow[t]{2}{*}{248} \\
\hline & & Antisense, 454: TCCTCCAGATTTTGCGGTTG* & & Antisense, 447: GATTTTGCGGTTGGTCTGCC & \\
\hline \multirow[t]{2}{*}{ GAD67 } & \multirow[t]{2}{*}{ NM_008077.4 } & Sense, 83: ATGATACTTGGTGTGGCGTAGC ${ }^{*}$ & \multirow[t]{2}{*}{253} & Sense, 159: CAATAGCCTGGAAGAGAAGAGTCG & \multirow[t]{2}{*}{177} \\
\hline & & Antisense, 314: GTTTGCTCCTCCCCGTTCTTAG** & & Antisense, 314: GTTTGCTCCTCCCCGTTCTTAG & \\
\hline \multirow[t]{2}{*}{ M1R } & \multirow[t]{2}{*}{ NM_007698.3 } & Sense, 715: AGCAGCTCAGAGAGGTCACAGCCA & \multirow[t]{2}{*}{272} & Same as first PCR & \multirow[t]{2}{*}{272} \\
\hline & & Antisense, 987: GGGCCTCTTGACTGTATTTGGGGA & & & \\
\hline \multirow[t]{2}{*}{$M 2 R$} & \multirow[t]{2}{*}{ NM_203491.1 } & Sense, 682: CAAGACCCGGTGTCTCCCAGTCTA & \multirow[t]{2}{*}{368} & Same as first $P C R$ & \multirow[t]{2}{*}{368} \\
\hline & & Antisense, 1050: TGACGATCCAACTAGTTCTACTGT & & & \\
\hline \multirow[t]{2}{*}{ M3R } & \multirow[t]{2}{*}{ NM_033269.4 } & Sense, 814: ACAGAAGCGGAAGCAGAAAACTTT & 560 & Same as first $P C R$ & 56 \\
\hline & & Antisense, 1374: TTTGAAGGACAGAGGTAGAGCGGC & & & \\
\hline M4R & NM_007699.2 & Sense, 700: AAGGAGAAGAAGGCCAAGACTCTG & 446 & Same as first $P C R$ & \\
\hline & & Antisense, 1145: ACGAGCGATGCTGGCAAACTTTCG & & & \\
\hline M5R & NM_205783.1 & Sense, 907: TGTAGCAGTTGCCCCTCTTCAGAG & 197 & Same as first $P C R$ & 19 \\
\hline & & Antisense, 1104: AGCAGCACCTGGAGACAGGAAGTA & & & \\
\hline NPY & NM_023456.2 & Sense, 16: CGAATGGGGCTGTGTGGA* & 297 & Sense, 38: CCCTCGCTCTATCTCTGCTCGT & 220 \\
\hline & & Antisense, 289: AAGTTTCATTTCCCATCACCACAT & & Antisense, 236: GCGTTTTCTGTGCTTTCCTTCA & \\
\hline PV & NM_013645.3 & Sense, 104: GCCTGAAGAAAAAGAACCCG & 275 & Sense, 122: CGGATGAGGTGAAGAAGGTGT & \\
\hline & & Antisense, 275: AATCTTGCCGTCCCCATCCT & & Antisense, 265: TCCCCATCCTTGTCTCCAGC & \\
\hline SST & NM_009215.1 & Sense, 1: ATGCTGTCCTGCCGTCTCCA* & 250 & Sense, 41: GCATCGTCCTGGCTTTGGG & 1 \\
\hline & & Antisense, 231: GCCTCATCTCGTCCTGCTCA* & & Antisense, 191: GGGCTCCAGGGCATCATTCT & \\
\hline SST intron & Same as SST & Sense, 8: CTGTCCCCCTTACGAATCCC & 220 & Sense, 16: CTTACGAATCCCCCAGCCTT & 182 \\
\hline & & Antisense, 228: CCAGCACCAGGGATAGAGCC & & Antisense, 178: TTGAAAGCCAGGGAGGAACT & \\
\hline VGLUT1 & NM_182993.2 & Sense, 124: CCCTTAGAACGGAGTCGGCT & 593 & Sense, 148: ACGACAGCCTTTTGCGGTTC & \\
\hline & & Antisense, 697: TATCCGACCACCAGCAGCAG & & Antisense, 495: CAAAGTAGGCGGGCTGAGAG & \\
\hline VIP & NM_011702.2 & Sense, 216: TTATGATGTGTCAAGAAATGC & 424 & Sense, 253: GGAGTTTTCACCAGCGATTACAG & 225 \\
\hline & & Antisense, 616: TTTTATTTGGTTTTGCTATGGAAG* & & Antisense, 455: CTCACTGCTCCTCTTTCCATTCA & \\
\hline
\end{tabular}

Note: Position 1, first base of the start codon.

albumin in PBS. After blocking, slices were placed in rabbit anti-vAChT (1:1000; Synaptic Systems GmBH) and mouse anti-PV (Sigma) overnight at $4^{\circ} \mathrm{C}$ (Fortune and Lurie, 2009). Sections were then washed $3 \times 15$ min in PBS and placed in secondary antibodies goat anti-rabbit Alexa 488 (1:1000, Invitrogen) and goat anti-mouse Alexa 633 (1:1000, Invitrogen) for $60 \mathrm{~min}$. Sections were then washed $3 \times 15 \mathrm{~min}$ in PBS, mounted in Vectashield, and coverslipped. Confocal stacks were taken with Olympus Fluoview FV1000 confocal microscopy system equipped with an Olympus XLPlan N $25 \times$ objective with $2.4 \times$ zoom. Red/green channels in Figure $2 B$ were switched for consistency with Figure $2 A$. Results similar to those in Figure $2 B$ were obtained for the Millipore Bioscience Research Reagents goat anti-vAChT antibody. For negative controls, primary antibody was omitted to assess nonspecific binding.

GAD65-GFP and PV-GFP immunocytochemistry. Three- to 4-weekold mice were perfused transcardially using a $0.1 \mathrm{M}$ PBS solution containing 4\% PFA, the brain dissected and immersed in 4\% PFA for 1 or $3 \mathrm{~h}$. Brains were cryoprotected using $20 \%$ sucrose/PBS solution, and sectioned at $40 \mu \mathrm{m}$ using a freezing microtome. Free-floating sections were blocked for $2 \mathrm{~h}$ at room temperature in a PBS/0.5\% Triton X-100/1\% BSA/10\% normal goat serum (NGS) solution before being incubated overnight or $48 \mathrm{~h}(\mathrm{CCK})$ at $4^{\circ} \mathrm{C}$ with primary antibodies diluted in a $\mathrm{PBS} / 0.5 \%$ Triton $\mathrm{X}-100 / 1 \%$ bovine serum albumin (BSA)/1\% normal goat serum (NGS) solution (PBS-BG). Slices were washed 3 times for $20 \mathrm{~min}$ at room temperature with PBS-BG before being incubated for $2 \mathrm{~h}$ with secondary antibodies diluted in PBS-BG. After several washes in PBS, slices were mounted on gelatin-coated slides with Vectashield (Vector laboratories). Fluorescent images were captured with a Zeiss LSM510 confocal system. The following antibodies were used: mouse anti-PV (1:1000; Sigma), rabbit anti-SOM (1:500; DAKO), rabbit anti-NPY (1:500; Immunostar), rabbit anti-VIP (1:500; Immunostar), mouse anti-CR (1:500; Millipore), rabbit anti-CB (1:500; Millipore), mouse anti-cholecystokinin (CCK) (1:1000; gift from Dr. Gordon V. Ohning, Center for Ulcer Research and Education, University of California, Los Angeles, CA), goat antirabbit Alexa Fluor 555 (1:500; Invitrogen), goat anti-mouse Alexa Fluor 633 (1:500; Invitrogen), chicken anti-GFP (1:1000, Aves Labs), and goat anti-chicken Alexa Fluor 488 (1:500, Invitrogen).

\section{Results}

Identification of neurochemically distinct CA1 hippocampal BC subtypes using two different GFP mouse lines

Interneurons that target the perisomatic regions of CA1 PCs, also known as BCs, exist as two mutually exclusive interneuron subtypes, the PV- and cholecystokinin (CCK)-containing BCs (Freund and Katona, 2007). To facilitate selection of these interneuron subtypes, we used two lines of transgenic mice in which GFP labels subsets of hippocampal interneurons. We found that $79 \%$ (209/265) of GFP + cells from the B13 mice colocalized with PV but 0\% (0/184) colocalized with CCK (supplemental Fig. S1, available at www.jneurosci.org as supplemental material). In living slices, PV-GFP cells were sparsely detected in the CA1 hippocampus, with vertically oriented dendrites in the pyramidal cell layer. Of 40 recorded PV-GFP cells located in the CA1 pyramidal cell layer, 33 cells ( $15 \mathrm{WT}, 18 \mathrm{KO}$ ) could be unambiguously identified as PV BCs on the basis of their GFP fluorescence, vertical orientation of the dendrites, fast spiking phenotype, and axonal arborization restricted predominantly to stratum pyramidale (SP). The 7 remaining PV-GFP cells could not be unambiguously identified and were therefore not included in the study. Upon anatomical (Fig. 1A) and physiological (Fig. $1 B, G-I$ ) examination, PV-GFP cells were invariably found to be fast-spiking BCs. 

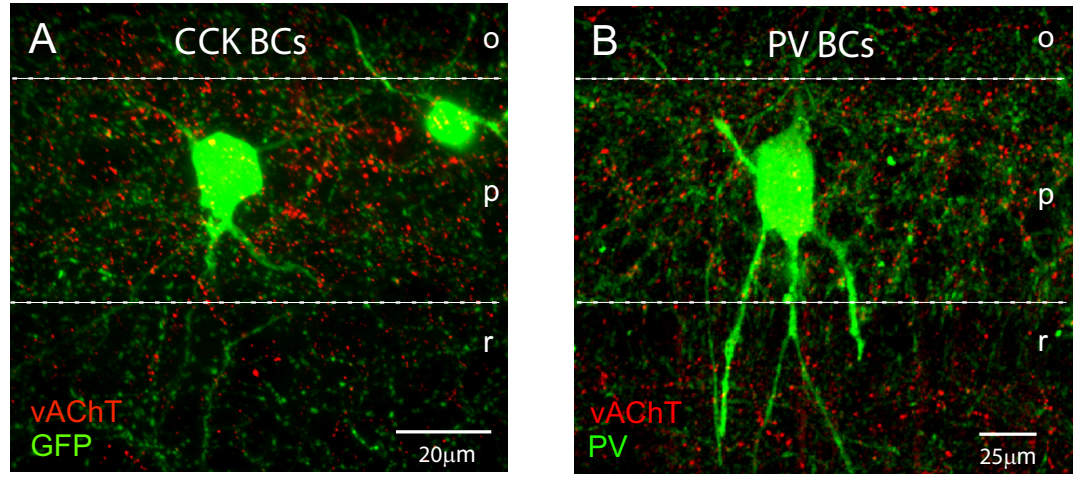

C

Pre

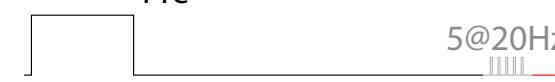

D

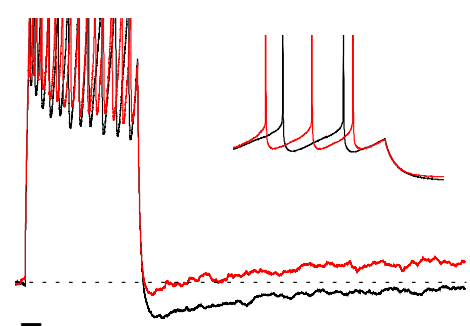

$\mathrm{F}$
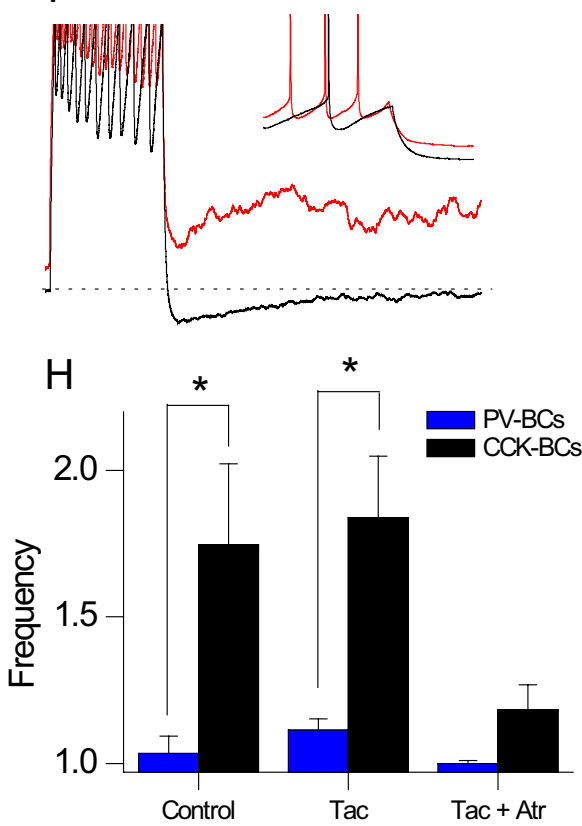

$\mathrm{E}$

G
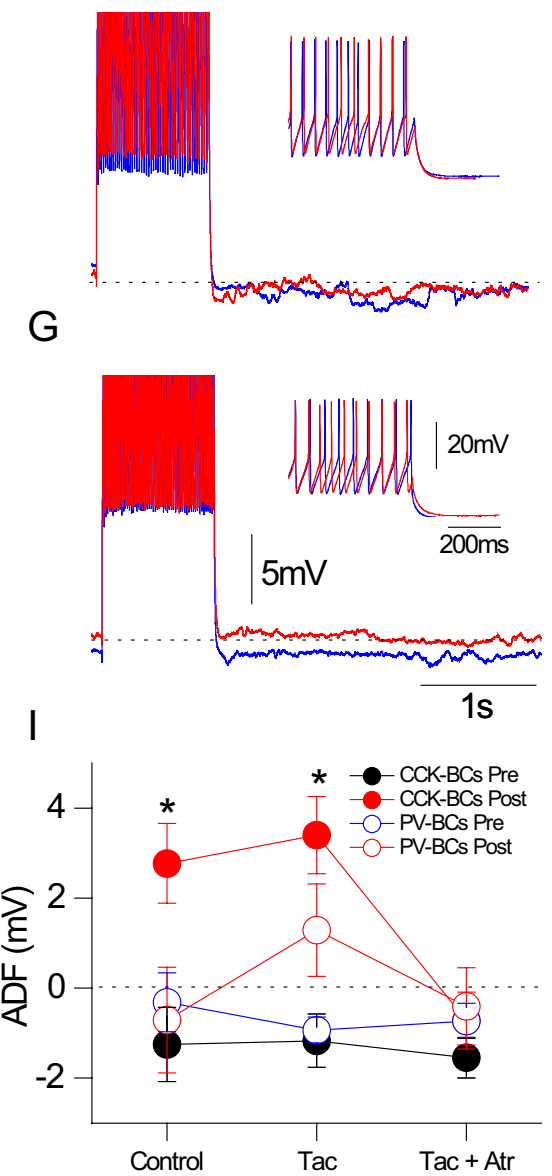

Figure 2. $\quad \mathrm{PV}$ and $C \mathrm{CK} B C$ s are sensitive to acetylcholine synaptic release. $\boldsymbol{A}, \boldsymbol{B}$, Images of $2 \mathrm{D}$ flat projections of three-dimensional confocal image stacks of vAChT-immunoreactive terminal labeling (red) in the vicinity of GAD65-GFP $(\boldsymbol{A})$ or PV $+(\boldsymbol{B})$ cells (green). SO, SP, and SR are denoted by 0, p, and r, respectively. C, Schematic showing protocol for cholinergic fiber stimulation, 5 pulses at $20 \mathrm{~Hz}$, flanked by a "pre" (black) and "post" (red) $1 \mathrm{~s}$ depolarizing test pulse. D, E, Representative traces during prestimulation (black or blue) and post (red)-20 Hz stimulation epochs performed in a CCK BC (D) or PV BC (E). Action potentials have been truncated in $\boldsymbol{D}$ and $\boldsymbol{E}$ for clarity. $\boldsymbol{F}, \boldsymbol{G}$, Representative traces during prestimulation (black) and post (red)-20 Hz stimulation epochs performed in a $C C K B C(F)$ or PVBC $(\boldsymbol{G})$ in the presence of $20 \mu \mathrm{m}$ tacrine. Insets in $\boldsymbol{D}-\boldsymbol{G}$ illustrate expanded regions at the end of the current step to illustrate changes in AP frequency during the poststimulation epoch. $\boldsymbol{H}$, Summary plot of the frequency ratio (poststimulation/prestimulation) in control, tacrine, and atropine conditions in PV and CCK BCs. I, Summary plot of the ADF before and after the stimulation in PV and CCK BCs. The dotted line at $0 \mathrm{mV}$ indicates the initial baseline voltage before the current step.

We also took advantage of transgenic mice in which EGFP is driven by a fragment of the GAD65 promoter (López-Bendito et al., 2004). These mice will be referred to throughout the manuscript as GAD65-GFP mice. GAD65-GFP interneurons were composed of a number of neurochemically distinct interneuron subtypes, with the conspicuous exception of $\mathrm{PV}+$ cells (supplemental Figs. S2, S3, available at www.jneurosci. org as supplemental material). We targeted GAD65-GFP neurons at the border of SP and SR, which are enriched in CCKcontaining subpopulations, including CCK BCs and Schaeffer collateralassociated cell types (Neu et al., 2007; Daw et al., 2009). Of 164 GAD65-GFP cells (87 WT, $77 \mathrm{KO}$ ) with cell bodies located in CA1 SP or SR, 74 cells (45\%) were identified as CCK BCs on the basis of their regular spiking phenotype and axonal arborization predominantly in SP. In accordance with previously published work in the dentate gyrus (Ledri et al., 2009), we observed that no GFP + cells colocalized with PV (supplemental Fig. S3, available at www.jneurosci.org as supplemental material). Moreover, GAD65-GFP interneurons that were morphologically confirmed to be BCs (Fig. 1C) exhibited a regular spiking phenotype (Fig. 1D), consistent with our initial characterization of this mouse line (Daw et al., 2009). GAD65-GFP interneurons have also been shown to be regular spiking in thalamus (Verbny et al., 2006) and neocortex (Sun et al., 2009).

To further confirm the neurochemical identity of PV-GFP BCs and GAD65-GFP BCs, we performed single-cell RT-PCR (scRT-PCR) on a subset of cells (Fig. $1 E, F)$. To this end, we examined 9 different interneuron markers, which included GAD65, GAD67, calcium binding proteins $[\mathrm{PV}, \mathrm{CB}$, and calretinin $(\mathrm{CR})]$, and neuropeptides [NPY, SOM, CCK, and VIP]. Both cell types were positive for GAD65 and/or GAD67 transcripts confirming their GABAergic phenotype (Fig. $1 E, F)$. As expected, in $8 / 8 \mathrm{PV}-\mathrm{GFP}$ BCs were PV positive and CCK negative (Fig. $1 E)$. Conversely, 17/17 GAD65-GFP BCs expressed CCK mRNA (Fig. $1 F$ ), further supporting that PV-GFP BCs are PV BCs and GAD65-GFP BCs are CCK BCs. In agreement with previous reports on cortical BCs, a subset of GAD65-GFP BCs also expressed PV transcript (Markram et al., 2004; Toledo-Rodriguez et al., 2005). Although we detected PV mRNA in these cells, none of these exhibited a fast spiking firing characteristic of PV BCs. In contrast to an AP half-width of $0.42 \pm 0.02 \mathrm{~ms}$ in PV BCs (see Fig. $4 E$ ), the AP half-width of CCK BCs containing or lacking PV mRNA was $0.89 \pm 0.06 \mathrm{~ms}(n=7)$ and $1.11 \pm 0.10 \mathrm{~ms}(n=9)$, respectively. Since these two populations were not significantly different (unpaired $t$ test $p=0.09$ ), data from CCK BCs containing or lacking PV mRNA were therefore pooled. 
Despite both PV BCs and CCK BCs sharing similar dendritic and axonal arborizations (Glickfeld and Scanziani, 2006; Földy et al., 2007), the two BC populations exhibited substantial differences in both passive (Fig. $1 G$ ) and active membrane properties (Fig. $1 H, I$ ). First, consistent with the observation that AP firing was triggered in CCK BCs with a smaller current step than in PV BCs (Fig. $1 B, D)$, the input resistance of PV BCs $(75.7 \pm 13.1 \mathrm{M} \Omega$, $n=15$ ) was substantially lower than of CCK BCs (Fig. $1 G ; 174 \pm$ $17 \mathrm{M} \Omega, n=23$, unpaired $t$ test $p=3.5^{\star} 10^{-5}$ ). Moreover, CCK $\mathrm{BCs}$ exhibited greater spike frequency accommodation than PV BCs, as indicated by different values of adaptation coefficient across a range of current step injections (Fig. 1 I; PV BCs, 300 pA: $0.72 \pm 0.05, n=10$; CCK BCs, 300 pA: $0.24 \pm 0.03, n=16$, unpaired $t$ test $p=4^{\star} 10^{-7}$ ). At larger magnitude current steps (500 pA), AP frequency accommodation tended to limit the maximal frequency in CCK BCs ( $500 \mathrm{pA}: 48 \pm 4 \mathrm{~Hz}, n=17)$, whereas PV BCs were able to achieve a much higher frequency (500 pA: $103 \pm 10 \mathrm{~Hz}, n=15$, unpaired $t$ test $p=1.7^{\star} 10^{-4}$; Fig. $\left.1 H\right)$. Facilitated by the use of these GFP transgenic animals, we are therefore able to consistently target two neurochemically and electrophysiologically distinct subtypes of BCs.

\section{CCK BCs are more sensitive to synaptic release of $\mathrm{ACh}$ than PV BCs}

Are mAChRs present on PV BCs and CCK BCs activated upon synaptic release of ACh? As revealed by immunocytochemical labeling of the vAChT, cholinergic fibers form a dense network of terminals intermingled in the vicinity of both GAD65-GFP cells (Fig. $2 \mathrm{~A}$ ) and PV cells (Fig. 2 B), implying that released acetylcholine has the capacity to modulate both PV BCs and CCK BCs. Using bulk fiber stimulation in SO, a previous study by Cobb and colleagues successfully elicited cholinergic synaptic responses from BCs, but the neurochemical identity of these BCs was not determined (Widmer et al., 2006). We recorded from PV-GFP or GAD65-GFP interneurons approximately equidistant from a stimulating electrode placed in $\mathrm{SO}$ and identified recorded neurons as PV BCs or CCK BCs through post hoc biocytin processing and visualization of neuronal morphology. The stimulation protocol consisted of 5 pulses at $20 \mathrm{~Hz}$, flanked by $1 \mathrm{~s}$ current steps before ("pre") or after ("post") bulk fiber stimulation (Fig. 2C), performed in the presence of blockers of ionotropic and metabotropic glutamatergic and GABAergic receptors (see Materials and Methods). In CCK BCs, bulk fiber stimulation increased AP frequency $1.7 \pm 0.3$-fold (Fig. $2 D, H$ ); from $10.2 \pm 2.1 \mathrm{~Hz}$ to $17.0 \pm$ $3.4 \mathrm{~Hz}, p=0.012, n=5)$ and transformed the AHP $(-1.3 \pm 0.8$ $\mathrm{mV}$ ) to a slow ADP (Fig. 2D, $I ; 2.8 \pm 0.9 \mathrm{mV}, p=0.036, n=5$ ). However, bulk fiber stimulation failed to induce a significant increase in AP frequency in PV BCs (Fig. 2E, $H ; 1.0 \pm 0.1$-fold; from $54.5 \pm 8.5 \mathrm{~Hz}$ to $57.5 \pm 11.8 \mathrm{~Hz}, n=4, p=0.24)$ or significantly reduce the posttrain AHP (Fig. $2 E, I$; from $-0.3 \pm$ $0.7 \mathrm{mV}$ to $-0.7 \pm 1.2 \mathrm{mV}, p=0.32, n=4)$. Therefore, bulk fiber stimulation elicited larger effects on AP frequency (unpaired $t$ test $p=0.04$ ) and on the AHP (unpaired $t$ test $p=0.04$ ) in CCK BCs than in PV BCs.

One possible explanation for the differential effects of bulk fiber stimulation on CCK BC and PV BC subtypes is that PV BCs may require greater spatial spread or enhanced acetylcholine levels to "spill over" to mAChRs present on PV BCs. To test this hypothesis, we examined the effect of the cholinesterase inhibitor tacrine $(20 \mu \mathrm{M})$ on the response to bulk fiber stimulation. Under tacrine conditions, bulk fiber stimulation also enhanced AP frequency (Fig. $2 F, H ; 1.8 \pm 0.2$-fold, from $12 \pm 2.4 \mathrm{~Hz}$ to $20.6 \pm 2.5$ $\mathrm{Hz}, n=5, p=0.004$ ) and $\mathrm{ADP}$ (Fig. $2 F, H ; 3.4 \pm 0.9 \mathrm{mV}, p=$
0.005) in CCK BCs similar to that occurring in the absence of tacrine (unpaired $t$ test $p>0.05$ ). In PV BCs, in contrast to bulk fiber stimulation in control conditions, tacrine induced a detectable increase in AP frequency (Fig. 2G,H; $1.1 \pm 0.04$-fold, from $60 \pm 6.8 \mathrm{~Hz}$ to $67.5 \pm 9.9 \mathrm{~Hz}, n=4, p=0.049)$ and eliminated the AHP (Fig. $2 G, I$; from $-0.9 \pm 0.3 \mathrm{mV}$ to $1.3 \pm 1.0 \mathrm{mV}, p=$ 0.045). The addition of the broad spectrum $\mathrm{mAChR}$ antagonist atropine $(5 \mu \mathrm{M})$ in the extracellular solution significantly reduced the AP frequency effects of bulk fiber stimulation (Fig. $2 \mathrm{H}$ ), returning to control values in CCK BCs $(n=5, p=0.25)$ and PV $\mathrm{BCs}(n=4, p=0.07)$. Atropine also attenuated the ADP induced by bulk fiber stimulation in CCK BCs (from $3.4 \pm 0.9 \mathrm{mV}$ to $-0.7 \pm 0.6 \mathrm{mV}, n=5, p=0.003$ ) and PV BCs (from $1.3 \pm 1.0$ $\mathrm{mV}$ to $-0.4 \pm 0.8 \mathrm{mV}, n=4, p=0.3$; Fig. $2 I$ ). These findings demonstrate that synaptic release of ACh elicits differential effects on PV BCs and CCK BCs.

\section{PV BCs and CCK BCs exhibit distinct cholinergic response profiles upon $\mathrm{mAChR}$ activation}

To more completely characterize how $\mathrm{mAChR}$ activation alters the cellular excitability of BC subtypes, we applied a 1-s-long depolarizing current step every $20 \mathrm{~s}$ to both PV and CCK BCs while maintaining the cells at $-60 \mathrm{mV}$. Both BC subtypes showed characteristic firing patterns in response to 1-s-long depolarizing current steps (Fig. 3A), consistent with previous observations (Fig. 1). Because the input resistance of the PV BCs was lower than that of CCK BCs (Fig. 1G), a larger current step was used to induce continuous firing in PV BCs for these experiments. Following a one-min control period, the bath solution was then switched to one containing $10 \mu \mathrm{M}$ muscarine (Fig. $3 A$, red traces) while applying bias current to maintain the neurons at $-60 \mathrm{mV}$. $\mathrm{mAChR}$ activation increased AP frequency in both PV BC (from $50.2 \pm 3.9$ to $77.4 \pm 6.5 \mathrm{~Hz}, p=5^{\star} 10^{-4}, n=12$ ) and CCK BCs (from $8.7 \pm 1.2$ to $33.6 \pm 3.4 \mathrm{~Hz}, p=1^{\star} 10^{-7}, n=29$ ). When normalized to the firing frequency in control conditions, CCK BCs exhibited a $5.8 \pm 0.9$-fold higher $\mathrm{mAChR}$-induced increase in AP frequency, whereas in PV BCs, firing frequency increased only $1.7 \pm 0.2$-fold (Fig. $3 B$; unpaired $t$ test $p=1.2^{\star} 10^{-4}$ ). The $\mathrm{mAChR}$-induced increase in firing frequency in both cell types was associated with a decrease in AP accommodation during the current step, as quantified by changes in the adaptation coefficient in both PV BC (from $0.70 \pm 0.04$ to $1.1 \pm 0.1, p=7^{\star} 10^{-4}$, $n=12$ ) and CCK BCs (from $0.26 \pm 0.03$ to $0.66 \pm 0.08, p=$ $\left.1^{\star} 10^{-4}, n=15\right)$. When normalized to the adaptation coefficient in control conditions (Fig. 3C), CCK BCs exhibited a higher relative increase in AP adaptation coefficient (3.0 \pm 0.5 -fold) than PV BCs ( $1.5 \pm 0.1$-fold; unpaired $t$ test $p=0.01)$. This observation suggests that the $\mathrm{mAChR}$-induced increase in firing frequency can be accounted by the loss of spike frequency adaptation.

$\mathrm{mAChR}$ activation also altered the ADF in voltage following the $1 \mathrm{~s}$ current step in both PV BCs and CCK BCs (Fig. $3 A, D)$. In PV BCs, an AHP typically occurred in control conditions (Fig. $3 A,-1.4 \pm 0.2 \mathrm{mV})$, which was eliminated in the presence of 10 $\mu \mathrm{M}$ muscarine $(1.4 \pm 0.7 \mathrm{mV}, n=15, p=0.0013)$ and was not significantly different from the baseline voltage measured $500 \mathrm{~ms}$ before the current step ( $p=0.11)$. In contrast, in CCK BCs, $\mathrm{mAChR}$ activation transformed the AHP $(-1.6 \pm 0.2 \mathrm{mV})$ into an $\operatorname{ADP}\left(5.0 \pm 0.9 \mathrm{mV}, p=9^{\star} 10^{-8}, n=29\right)$.

Moreover, upon bath application of muscarine, the two BC subtypes depolarized to different extents, as indicated by the bias current needed to maintain the cells at $-60 \mathrm{mV}$ (Fig. 3E). PV BCs strongly depolarized upon $\mathrm{mAChR}$ activation, requiring signifi- 

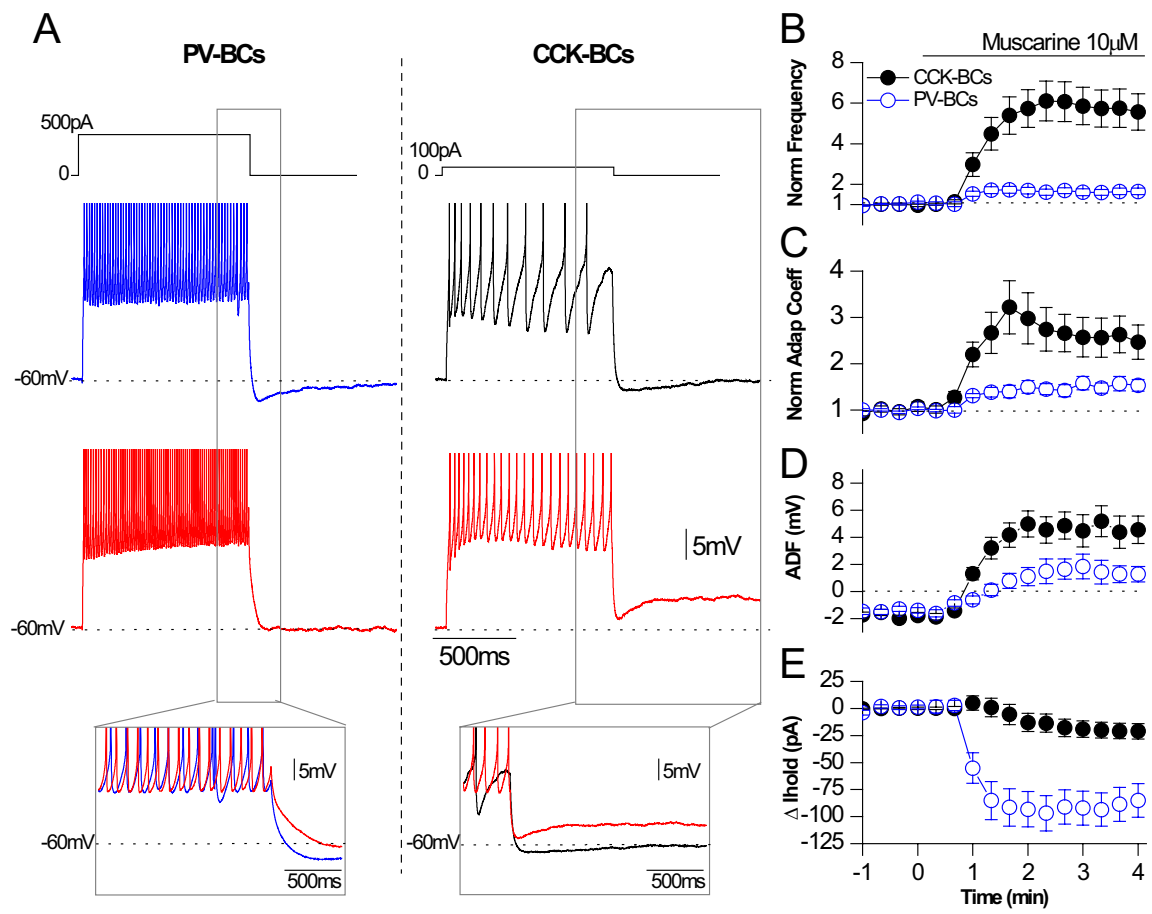

Figure 3. $P V B C s$ and $C C K B C s$ exhibit distinct cholinergic response profiles upon $m A C h R$ activation. $\boldsymbol{A}$, Voltage response from $-60 \mathrm{mV}$ in (blue and black) control and (red) after bath application of $10 \mu \mathrm{m}$ muscarine for PV BCs and CCK BCs, respectively. Bottom, Expanded, overlaid traces showing increased AP frequency and changes in ADF in the presence of muscarine. $B, C, A P$ frequency $(\boldsymbol{B})$ and adaptation coefficient $(\boldsymbol{C})$, normalized to the first minute in control conditions. $\boldsymbol{D}, \boldsymbol{E}, A D F s(\boldsymbol{D})$ in a $100 \mathrm{~ms}$ window $200 \mathrm{~ms}$ after the current offset and changes in holding current $(\boldsymbol{E})$ at $-60 \mathrm{mV}$ relative to control conditions. In $\boldsymbol{B}-\boldsymbol{E}$, muscarine was bath applied at time 0 as indicated by the bar in B. CCK BCs $(n=29)$ and PV BCs $(n=15)$ are denoted by closed and open symbols, respectively.

cantly more negative bias current compared with control conditions (from $-82 \pm 20 \mathrm{pA}$ to $-175 \pm 31 \mathrm{pA}, n=13, p=8^{\star} 10^{-5}$ ). Maintaining CCK BCs at $-60 \mathrm{mV}$ in the presence of $10 \mu \mathrm{M}$ muscarine also required additional negative bias current (from $-26 \pm 8.0 \mathrm{pA}$ to $-39 \pm 10 \mathrm{pA}, n=24, p=0.009)$, but was statistically less than in PV BCs (unpaired $t$ test $p=7^{\star} 10^{-4}$ ).

mAChR activation broadens APs in CCK BCs but not PV BCs To determine whether APs themselves were altered by mAChR activation, we analyzed the AP waveforms of PV BCs and CCK $\mathrm{BCs}$ during the current step in both control and $10 \mu \mathrm{M}$ muscarine conditions (Fig. 4). Under control conditions, APs in PV BCs were precise, exhibiting no significant changes in half-width throughout the current step (Fig. $4 A$, B, blue; Fig. $4 E ; 0.40 \pm 0.03$ ms, $n=12$ ) with very little jitter in the AP waveform (SD of half-width: $11 \pm 2 \mu \mathrm{s}, n=8)$. In contrast, CCK BCs exhibited a broader initial AP waveform (Fig. 4C, black; half-width $0.85 \pm$ $0.09 \mathrm{~ms}, n=16, p=0.004)$ that broadened further during the current step (Fig. $4 C, D$, black) and was associated with more jitter in the AP waveform (SD of half-width: $21 \pm 3 \mu \mathrm{s}, n=13$, unpaired $t$ test $p=0.01$ ). In addition, the peak negative $\mathrm{dV} / \mathrm{dt}$, a measurement of AP repolarization rate, differed significantly between PV BCs (blue; - 104.1 $\pm 5.8 \mathrm{mV}^{\star} \mathrm{ms}^{-1}, n=6, p=$ $2^{\star} 10^{-5}$ ) and CCK BCs (Fig. $3 F$, black; $-53.3 \pm 4.3 \mathrm{mV}^{\star} \mathrm{ms}^{-1}$, $n=15)$.

Although the AP half-width in PV BCs was insensitive to $\mathrm{mAChR}$ activation (first $100 \mathrm{~ms}$ : from $0.37 \pm 0.02 \mathrm{~ms}$ to $0.36 \pm$ $0.04 \mathrm{~ms}, p=0.05)$, mAChR activation selectively broadened the half-width in CCK BCs during the current injection step (Fig. $4 E$; first $100 \mathrm{~ms}$ : from $0.82 \pm 0.09 \mathrm{~ms}$ to $0.97 \pm 0.13 \mathrm{~ms}, p=0.01)$. Moreover, $\mathrm{mAChR}$ activation reduced the peak negative $\mathrm{dV} / \mathrm{dt}$ in CCK BCs (from - $53.3 \pm$ 4.3 to $-37.1 \pm 4.4, n=15, p=6.6 \mathrm{e}-5)$ but not in PV BCs (Fig. $4 F$; from $-104.1 \pm$ $5.6 \mathrm{mV} / \mathrm{ms}$ to $-79.6 \pm 8.5 \mathrm{mV} / \mathrm{ms}, n=6$, $p=0.06)$. Together, these experiments underscore that PV BCs and CCK BCs differ significantly in their response to mAChR activation. We conclude that $\mathrm{mAChR}$ activation of hippocampal BCs is cell type specific, depending on neurochemical identity.

\section{Frequency and activity dependence of mADP generation in CCK BCs}

Because the different passive and active properties of each BC subtype converge to yield different initial firing frequencies when depolarizing current steps were introduced (Fig. 1), it was not clear whether the presence of a mAChR-induced ADP was intrinsically cell type specific, or simply due to differences in the preexisting level of overall cellular excitability. To determine whether the effects of mAChR activation remained different if firing frequencies were the same between PV BCs and CCK BCs, we designed protocols that introduced APs at identical frequencies and numbers in both PV BCs and CCK BCs, traversing the physiological range of firing for both cell types. First, to examine the AP frequency dependence of the MADP, we systematically varied the AP frequency $(1-100 \mathrm{~Hz}$ ) in PV BCs (Fig. $5 A$ ) and CCK BCs (Fig. 5B) over a $1 \mathrm{~s}$ epoch in control conditions or in the presence of $10 \mu \mathrm{M}$ muscarine. In PV BCs, no significant $\mathrm{ADP}$ was generated at any frequency, exhibiting only a loss of the AHP at higher frequencies $(50$ and $100 \mathrm{~Hz} ; 0.03 \pm 0.3 \mathrm{mV}, n=6$, $p=0.03$; Fig. $5 C, D)$. In contrast, in CCK BCs, a significant mADP was elicited in response to frequencies between 2 and $50 \mathrm{~Hz}(p<$ $0.05)$, with a peak $\mathrm{ADP}$ occurring at $20 \mathrm{~Hz}(3.2 \pm 0.8 \mathrm{mV}, n=5$, $p=0.004$; Fig. $5 E, F)$. Interestingly, at frequencies of 50 and 100 $\mathrm{Hz}$, the voltage response became biphasic in CCK BCs; the medium duration AHP was superimposed on the ADP, particularly during the first $500 \mathrm{~ms}$ after the offset of the current step (Fig. 5B, bottom). This medium duration AHP reduced the ADP, creating the biphasic response profile (Fig. $5 F$ ).

Next, to examine the activity dependence of the ADP, we varied the AP number (1-100 APs) in PV BCs and CCK BCs (Fig. 6). Because the $\mathrm{mAChR}$-induced ADP for CCK BCs peaked at a frequency of $20 \mathrm{~Hz}$, we chose this frequency to examine AP number. Using this protocol, PV BCs exhibited no significant ADP over the entire range of APs $(p>0.05$; Fig. $6 A-C)$. However, CCK BCs showed a significant gain of ADP between 1 and 50APs, with a peak at $10 \mathrm{APs}(5.7 \pm 2.1 \mathrm{mV}, n=6, p=0.02$; Fig. $6 A, D, E)$. These results demonstrate that the threshold for activation of ADPs in CCK BCs critically depends both on the frequency and duration of AP firing, whereas appreciable ADPs are not generated in PV BCs despite varying both frequency and AP number across a broad range. 

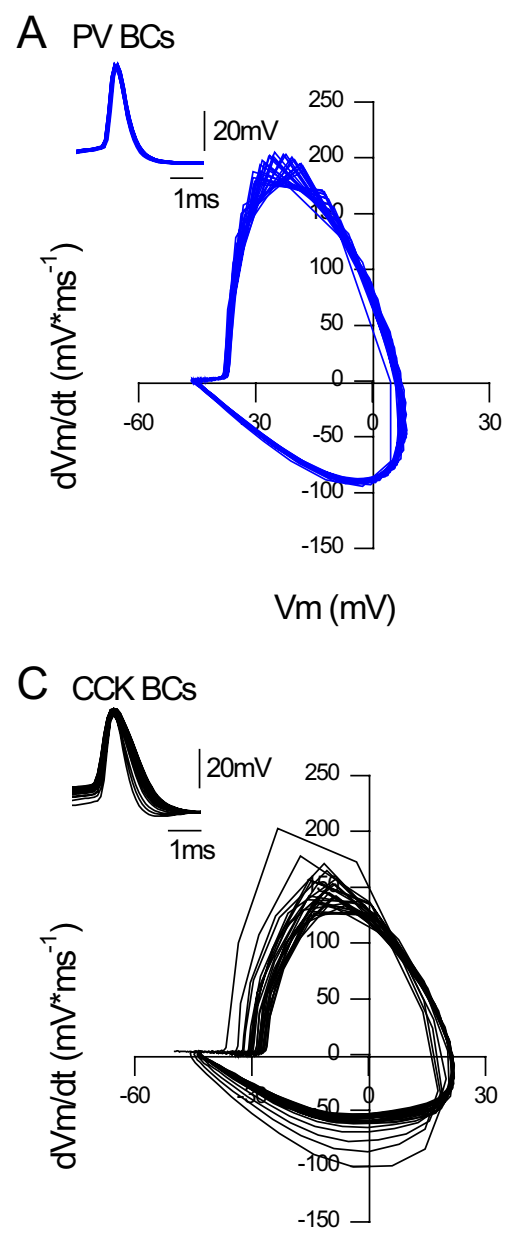

$\mathrm{Vm}(\mathrm{mV})$
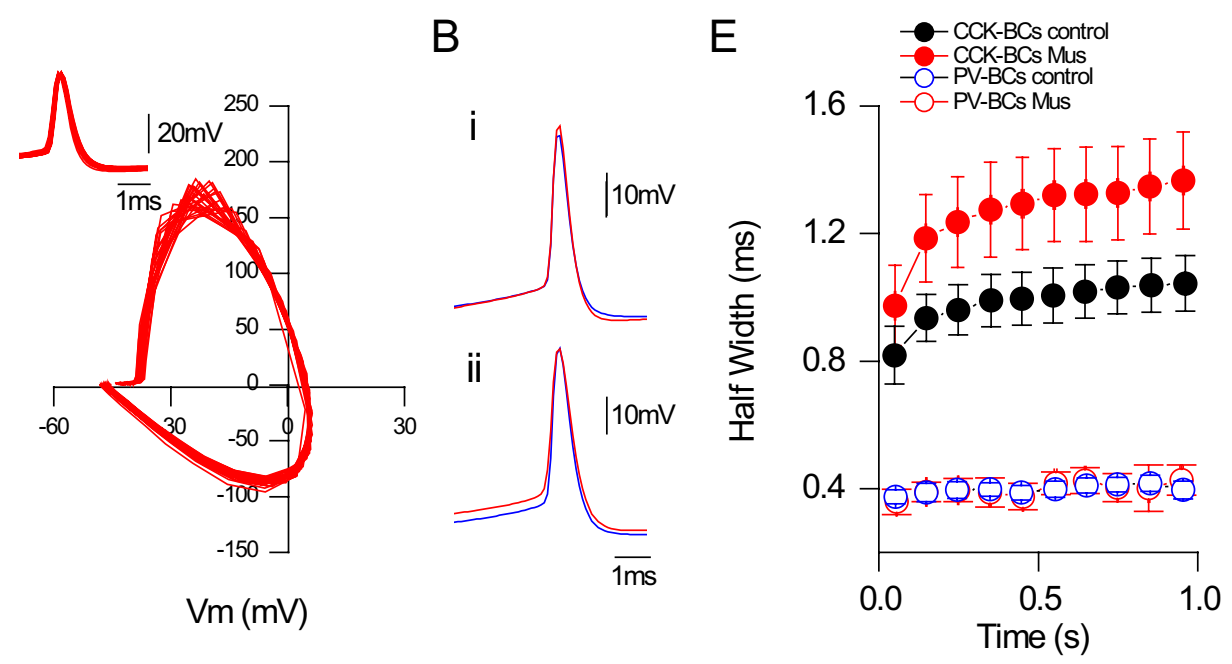

$\mathrm{D}$

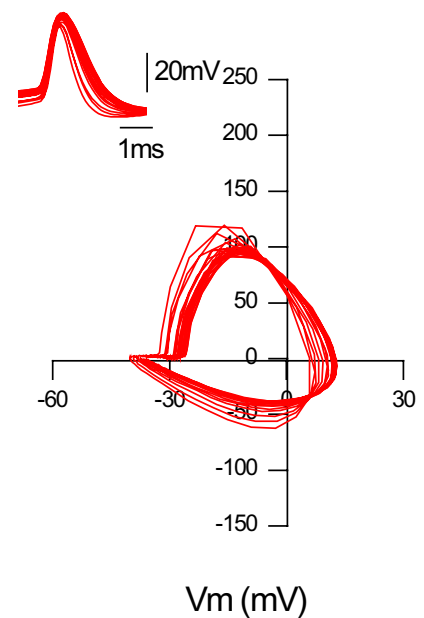

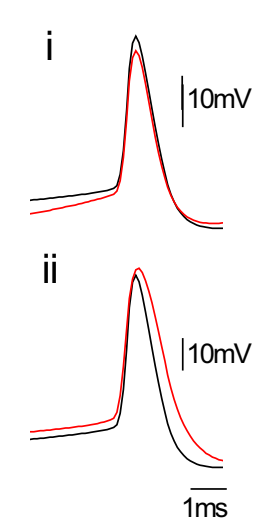

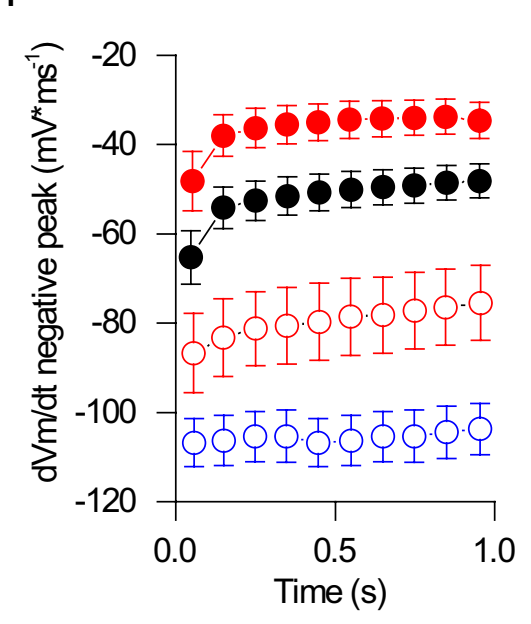

Figure 4. $m A C h R$-induced modulation of $A P$ waveform in PV BCs and CCKBCs. $A, B$, Representative phase plots of dV/dt vs Voltage of the first 26 consecutive $A P s$ for PV BC (blue) (A) and CCK BCs $(\boldsymbol{B})$ in control conditions (black) and after bath application of $10 \mu \mathrm{m}$ muscarine (red). Insets illustrate the APs overlaid. C, D, Phase plots for 26 consecutive APs for PV BCs (C) and CCK BCs (D). C, Average AP waveform during the first (i) or last (ii) $100 \mathrm{~ms}$ of the $1 \mathrm{~s}, 300 \mathrm{pA}$ current step in control (blue and black) and $10 \mu \mathrm{m}$ muscarine (red) conditions for PV BCs (C) and CCK BCs (D). E, AP half-width, binned in $100 \mathrm{~ms}$ intervals during the $1 \mathrm{~s} \mathrm{current} \mathrm{step} \mathrm{for} \mathrm{a} \mathrm{population} \mathrm{of} 6$ PV BCs (open symbols) and 15 CCK BCs (closed symbols), respectively, in control (blue and black) and $10 \mu \mathrm{M}$ muscarine (red) conditions. $\boldsymbol{F}$, Similar to $\boldsymbol{E}$, but plotted for $\mathrm{dV} / \mathrm{d}$ t negative peak.

\section{The presence of M3 mAChRs distinguishes CCK BCs from PV BCs}

Do the distinct cholinergic phenotypes of PV BCs and CCK BCs involve the differential expression of $\mathrm{mAChR}$ subtypes? Using a combination of scRT-PCR, GAD65 and PV-GFP mice crossed with $\mathrm{mAChR}$ knock-out mice, and $\mathrm{mAChR}$ subtype-specific antagonists, we explored this question in PV BCs and CCK BCs.

To examine the molecular identities of $\mathrm{mAChRs}$ on PV BCs and CCK BCs, we first performed scRT-PCR, probing each cell type for all mAChR subtypes (M1-M5). PV BCs expressed M1 mAChR mRNA but entirely lacked M3 mRNA (Fig. 7A). In contrast, in CCK BCs, robust mRNA expression of both M1 and M3 mAChRs was detected (Fig. 7B).

To determine whether the M1 mAChR contributes to the $\mathrm{mAChR}$-induced changes in firing frequency and mADP, we crossed M1 knock-out mice with PV-GFP mice to obtain PV BCs lacking M1 mAChRs. First, the mAChR-induced increase in firing frequency was completely absent in PV BCs from M1 KO mice $(66 \pm 6 \mathrm{~Hz}$ to $70 \pm 2 \mathrm{~Hz}, n=4, p=0.52$; Fig. $7 D, E)$. Second, in contrast to WT animals, the AHP in PV BCs from M1 $\mathrm{KO}$ mice was resistant to $\mathrm{mAChR}$-induced modulation (Fig. $7 F$; from $-3.8 \pm 0.4 \mathrm{mV}$ to $-3.0 \pm 0.5 \mathrm{mV}, n=4, p=0.24)$. Third, the initial holding current at $-60 \mathrm{mV}$ in control conditions did not differ between PV BCs in WT or M1 KO (unpaired $t$ test $p=$ 0.1 ), but the $\mathrm{mAChR}$-induced increase in holding current in WT animals $(-175 \pm 31 \mathrm{pA}, n=13)$ was greatly attenuated in PV BCs lacking M1 mAChRs ( $-25 \pm 11 \mathrm{pA}, n=4$, unpaired $t$ test $\left.p=8.3^{\star} 10^{-5}\right)$. We also examined the effect of the M1 antagonist telenzepine (100 nM). Consistent with our results in the M1 KO mouse, telenzepine blocked the mAChR-induced reduction in AHP in WT PV BCs $(-1.1 \pm 0.4, n=10, p=0.4$; supplemental Fig. $S 4 B$, available at www.jneurosci.org as supplemental material). Prompted by immunocytochemical evidence that PV BCs possess M2 mAChRs (Hájos et al., 1998), we crossed PV-GFP and $\mathrm{M} 2 \mathrm{KO}$ mice. mAChR modulation in PV BCs was not significantly different in M2 KO and WT mice (supplemental Fig. $S 4 A, B$, available at www.jneurosci.org as supplemental material). Together, these findings converge on the M1 mAChR subtype as the predominant $\mathrm{mAChR}$ subtype mediating the cholinergic phenotype of PV BCs.

To examine the contribution of M1 mAChRs to the cholinergic phenotype of CCK BCs, we crossed GAD65-GFP and 
A

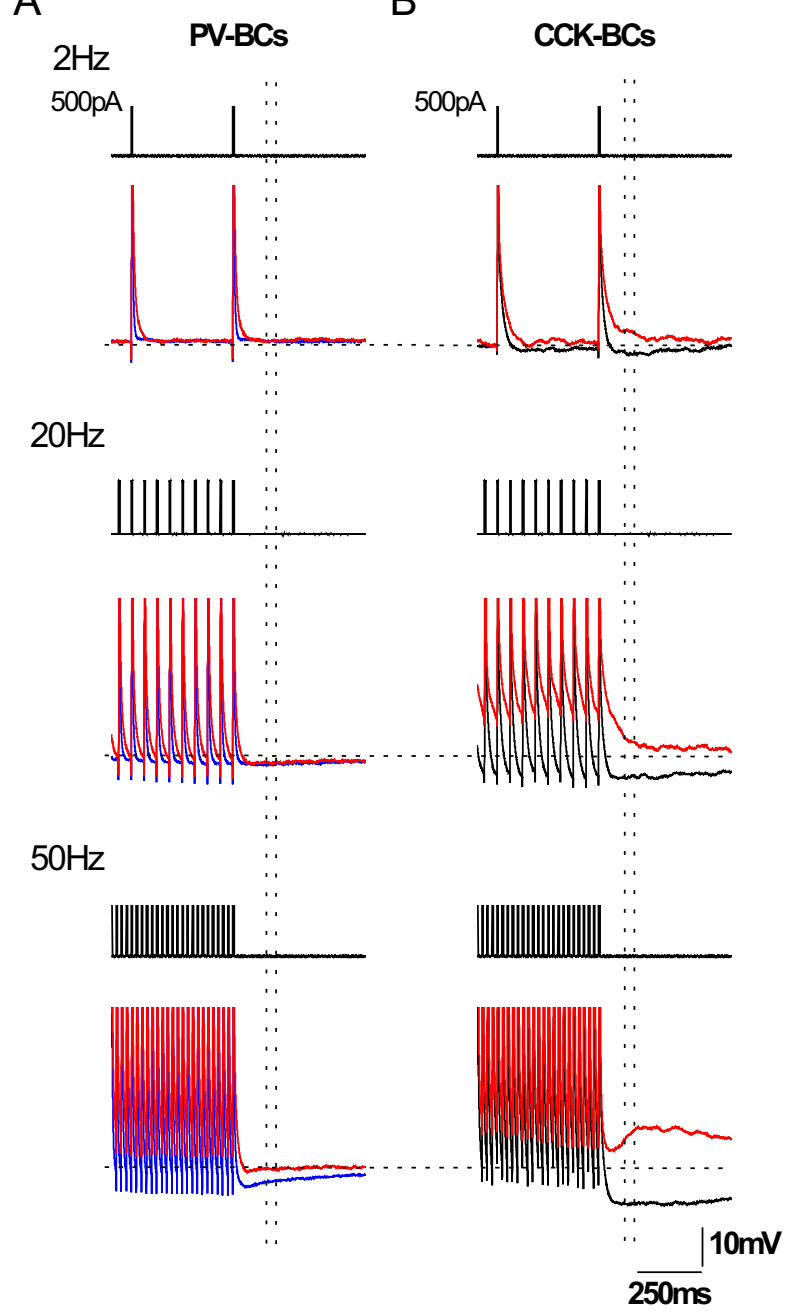

C
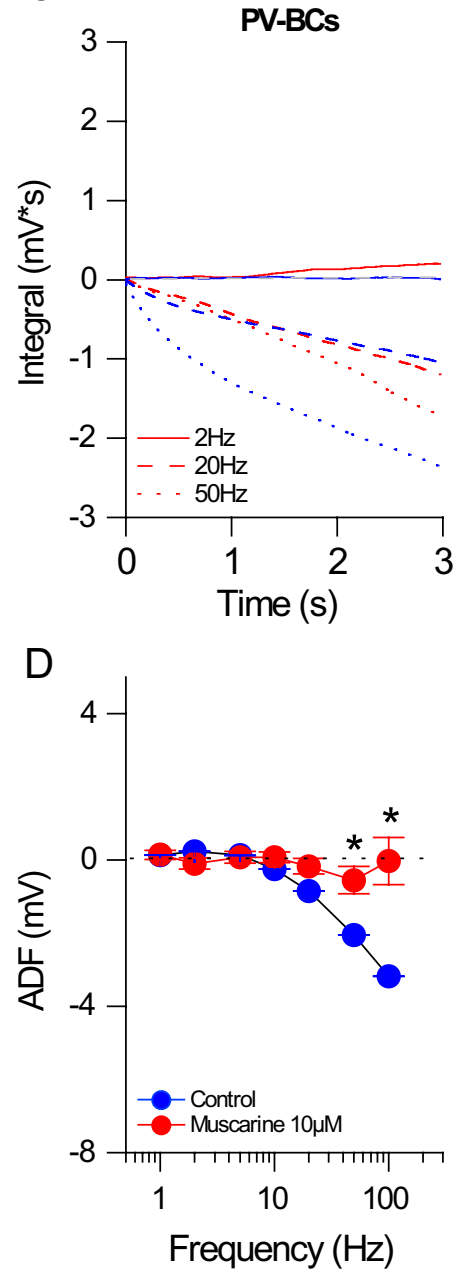

$E$

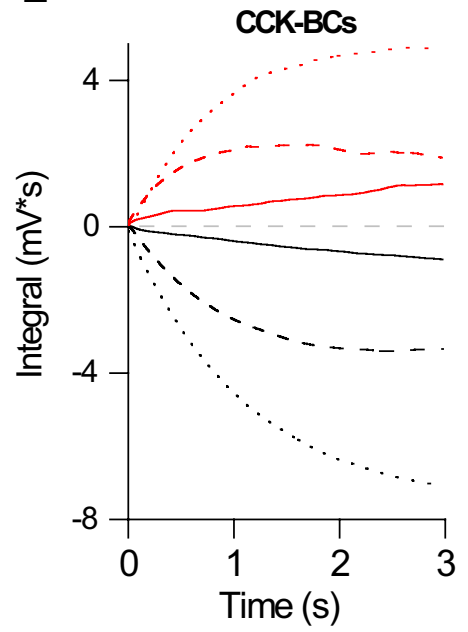

$\mathrm{F}$

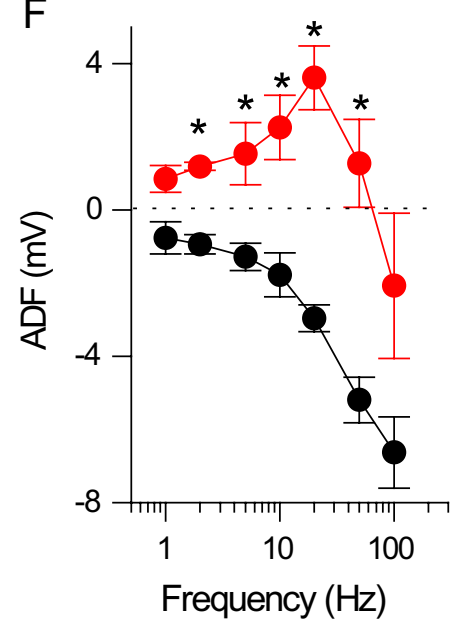

Figure 5. AP frequency dependence of the $\mathrm{mAChR}$-induced $\mathrm{ADP}(1-100 \mathrm{~Hz}$ in $1 \mathrm{~s})$ in PV BC and CCK BC subtypes. $\boldsymbol{A}, \boldsymbol{B}$, Representative traces at 2,20 , and $50 \mathrm{~Hz}$ are shown for PV $(\boldsymbol{A})$ and $C C K(\boldsymbol{B})$

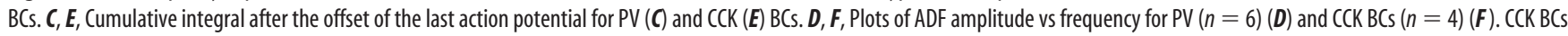
exhibited a peak ADP at $20 \mathrm{~Hz}$; in contrast, the ADP of PV BCs showed no frequency dependence. Vertical lines denote the area where ADF was measured. Asterisks denote $p<0.05$.

M1KO-GFP mice lines to obtain GAD65 BCs lacking M1 mAChRs. In contrast to PV BCs, the absence of M1 mAChRs had no effect on the mAChR-induced firing frequency in CCK BCs (unpaired $t$ test $p=0.8$ ), indicating that non-M1 mAChRs control firing frequency in CCK BCs (Fig. 7G,H). However, mAChR activation of M1-lacking CCK BCs reduced the AHP $(-0.2 \pm 0.8$ $\mathrm{mV}, n=3$ ) but, unlike WT mice (Fig. 7D, $5.0 \pm 0.9 \mathrm{mV}, n=29$ ), failed to develop an ADP (unpaired $t$ test $p=0.002$ ). Eliminating both M1 and M3 mAChRs from CCK BCs, achieved through crossing GAD65-GFP mice with the M1/M3 double KO mouse, blocked both the $\mathrm{mAChR}$-induced increase in firing frequency (Fig. $7 \mathrm{H} ; 12 \pm 3 \mathrm{~Hz}$ to $9 \pm 2 \mathrm{~Hz}, n=5, p=0.3$ ) and prevented the emergence of the mADP (Fig. $7 I$; from $-2.0 \pm 0.4 \mathrm{mV}$ to $-0.5 \pm$ $0.4, n=5, p=0.1)$. The $\mathrm{mAChR}$-induced increase in firing frequency and $\mathrm{mADP}$ in CCK BCs was also suppressed by preapplication of telenzepine (100 nM) in the M3 KO mouse (supplemental Fig. S4A, available at www.jneurosci.org as supplemental material). These data indicate that the cholinergic phenotype in CCK BCs involves both M1 and M3 mAChRs.

The cholinergic phenotype of CCK BCs in M3 KO mice also resembled that of WT PV BCs, inducing a modest increase in mAChR-induced firing frequency $(3.1 \pm 0.7$-fold, $n=9)$ that was not significantly different from that of WT PV BCs $(1.7 \pm 0.2$, $n=12$, unpaired $t$ test $p=0.09$ ) and reducing the AHP but not generating an ADP (WT PV BCs: $1.5 \pm 0.7 \mathrm{mV}, n=15$; CCK BCs in $\mathrm{M} 3 \mathrm{KO}: 0.2 \pm 0.5 \mathrm{mV}, n=9$; unpaired $t$ test $p=0.17)$. Indeed, M3 mAChR mRNA from CCK BCs in M3 KO mice (Fig. 7C) was not detected, generating a $\mathrm{mAChR} m \mathrm{mNA}$ expression profile that resembled WT PV BCs, where $\mathrm{M} 1 \mathrm{mAChR}$ mRNA dominates the mAChR mRNA expression profile (Fig. 7C).

Together, these observations indicate that M1 and M3 $\mathrm{mAChRs}$ both participate in the generation of the mADP in CCK $\mathrm{BCs}$, but muscarinic control of firing frequency is mediated primarily by $\mathrm{M} 1 \mathrm{mAChRs}$ in PV BCs and M3 mAChRs in CCK BCs. We conclude that the presence of M3 mAChRs is a key distinction between the cholinergic phenotypes of CCK BCs and PV BCs.

mAChR activation induces a long-lasting ADP induced by glutamatergic transmission in CCK BCs

We have shown that PV BCs and CCK BCs undergo increases in cellular excitability upon the introduction of suprathreshold current steps delivered through the recording electrode. Although this protocol is an excellent way of probing mAChR-induced modulation of intrinsic membrane properties, we were interested in whether more physiological stimuli, such as suprathreshold glutamatergic synaptic potentials, could evoke differential 
A

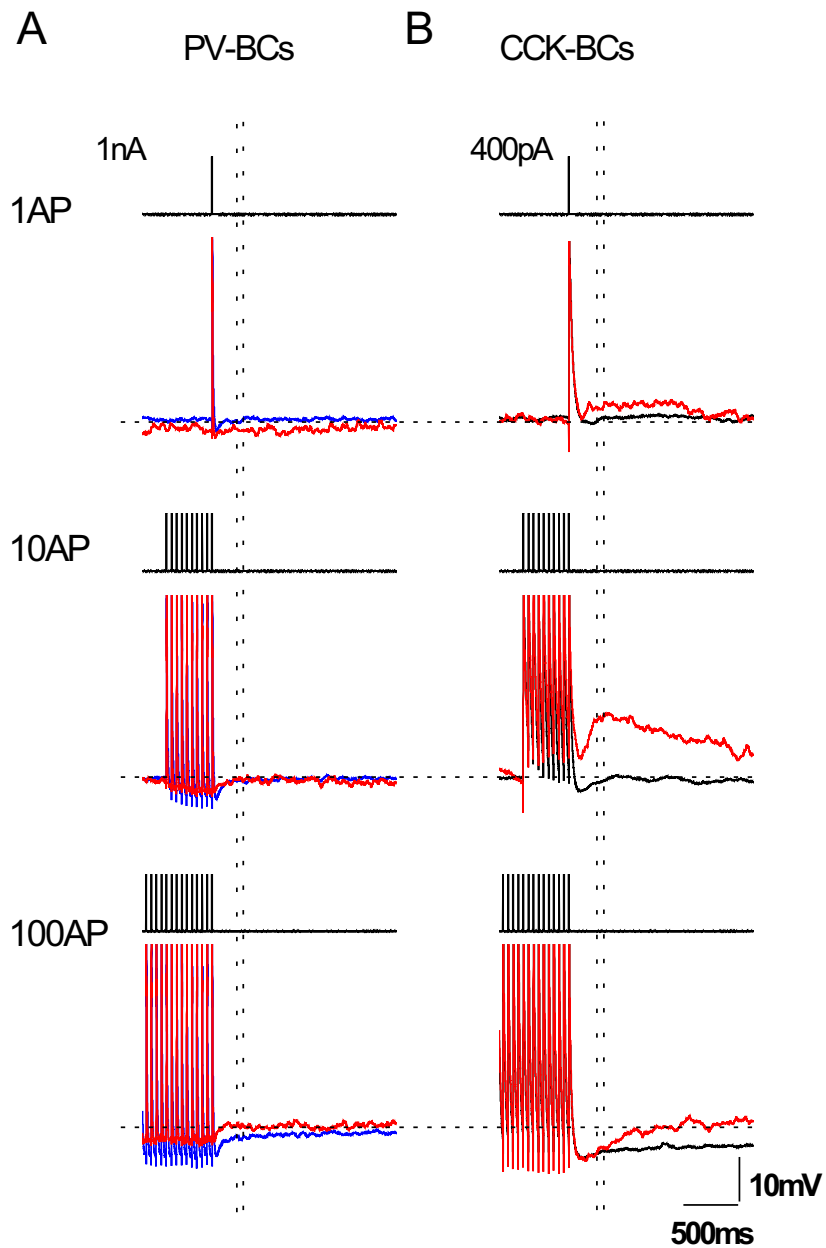

C
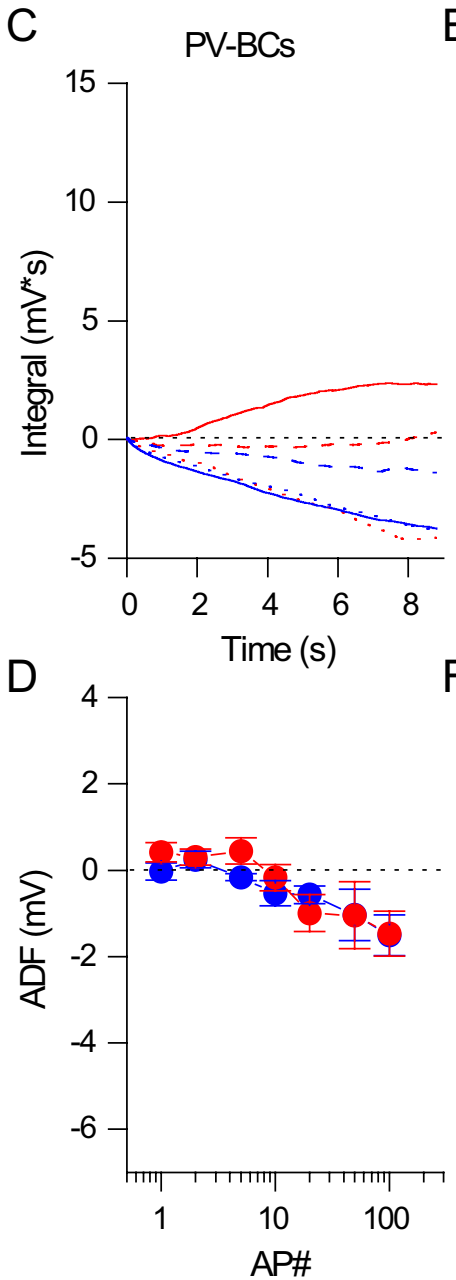

E
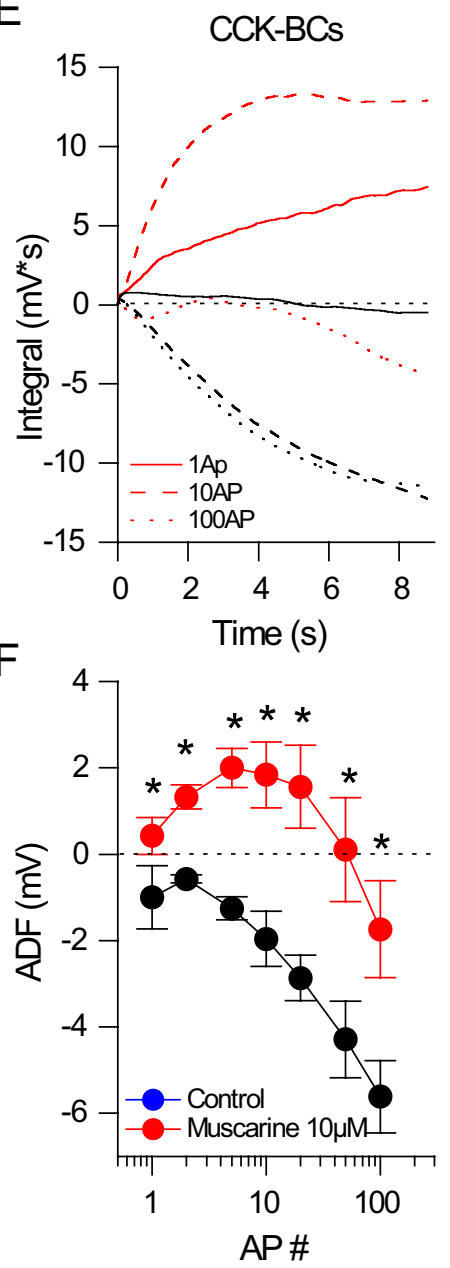

Figure 6. Activity dependence of $m A C h R$-induced ADPs. To examine the AP dependence of the $m A C h R$-induced $A D P$, we varied the AP number (1-100 APs at $20 \mathrm{~Hz}$ ) in CCK and PV BC subtypes. $\boldsymbol{A}, \boldsymbol{B}, \mathrm{PV}$ and $C C K \mathrm{BC}$ representative traces at 1,10 , and $100 \mathrm{APs}$ are shown, aligned at the offset of the last AP. $\boldsymbol{C}, \boldsymbol{E}$, Cumulative integral after the offset of the last AP for PV $(\boldsymbol{C})$ and $C(C K(\boldsymbol{E})$ BCs. $\boldsymbol{D}, \boldsymbol{F}$, Plots of ADF amplitude vs AP number for PV $(\boldsymbol{D})$ and CCK $(\boldsymbol{F})$ BCs. CCK BCs exhibited a peak ADP at 2-20 APs; in contrast, the ADF of PV BCs displayed no AP dependence.

mAChR-induced responses in CCK BCs and PV BCs. Both types of perisomatically innervating BCs receive glutamatergic afferent input via SCs (Glickfeld and Scanziani, 2006). To determine whether $\mathrm{mAChR}$ activation could alter the $\mathrm{BC}$ response to direct glutamatergic synaptic activation, we stimulated SCs to elicit near-action potential threshold EPSPs (EPSPs) in both PV BCs and CCK BCs (Fig. 8). Representative traces of single evoked EPSPs (Fig. $8 A$ ) or a train of 5 EPSPs at $20 \mathrm{~Hz}$ (Fig. $8 B, C$ ) are shown for PV BCs (Fig. $8 A-C$ ) and CCK BCs (Fig. $8 D-F$ ) under control conditions (black traces) and in the presence of $10 \mu \mathrm{M}$ muscarine (red traces) respectively. In a PV BC, a train of EPSPs elicited APs tightly locked with the synaptic stimulus (Fig. $8 B$, blue). Upon wash-in of $10 \mu \mathrm{M}$ muscarine, the holding current became progressively more negative, indicating a depolarization consistent with previous experiments (Fig. 3E). Moreover, a small reduction in EPSPs amplitude was occasionally observed, possibly due to presynaptic modulation (Seeger et al., 2004). In these cases, the stimulus strength was readjusted to match the amplitude of the control EPSP (McQuiston and Madison, $1999 \mathrm{~b})$. When synaptic stimuli were elicited at $20 \mathrm{~Hz}$ in the presence of muscarine, evoked EPSPs elicited APs at a similar discharge frequency as in control conditions (Fig. $8 B, C$ ). We then introduced the same synaptic stimulation protocol in CCK BCs, eliciting similar levels of excitation as PV BCs in control conditions (Fig. 8D-F, black traces). In contrast to PV $\mathrm{BCs}$, individual synaptic stimuli evoked a detectable ADP in the presence of muscarine (Fig. $8 D$, red). Remarkably, evoking 5 EPSPs at $20 \mathrm{~Hz}$ in CCK BCs induced a long-lasting ADP following the EPSP train (Fig. $8 \mathrm{E}$, red), resulting in prolonged high-frequency firing that occurred for $8 \mathrm{~s}$ after the termination of the synaptic stimulus.

We quantified these effects in a population of 4 anatomically identified PV BCs and 5 CCK BCs. Introducing 5 EPSPs at $20 \mathrm{~Hz}$ in CCK BCs generated suprathreshold APs during the train $(5.8 \pm 1.0 \mathrm{~Hz})$ that was increased in muscarine conditions $(22.2 \pm 4.5 \mathrm{~Hz}, p=0.03)$. Moreover, following the stimulus train, the AHP $(-2.5 \pm 1.3 \mathrm{mV})$ obtained in control conditions was transformed to a large $(10.2 \pm 2.5 \mathrm{mV})$, long-lasting $(5.3 \pm$ $0.9 \mathrm{~s}) \mathrm{ADP}$ in the presence of muscarine $(p=0.003, n=5$; Fig. $8 G$, closed circles). During the ADP, APs persisted at a similar frequency $(14.8 \pm 2.2 \mathrm{~Hz})$ as during the train $(p=0.2)$. In contrast, in PV BCs, mAChR activation had no effect on the number of APs evoked during the EPSP train (from $8.0 \pm 2.7$ to $9.0 \pm 2.4 \mathrm{mV}, p=0.81$ ) or the ADF following the EPSP train (from $-0.9 \pm 0.2 \mathrm{mV}$ to $0.5 \pm 0.9 \mathrm{mV}, p=0.2$; Fig. $8 G$, open circles, unpaired $t$ test $=0.013$ ). Because the duration of the AHP and ADP were variable, we also quantified the integral of the ADF in both PV BC and CCK BC cell types (Fig. $8 H$ ). In the presence 
A

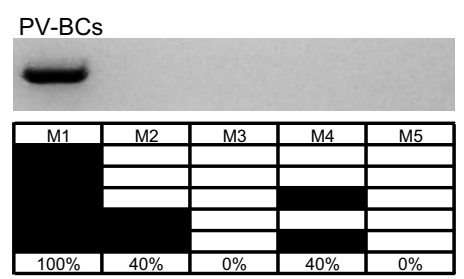

B

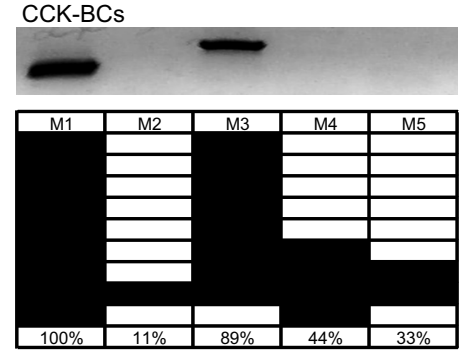

C

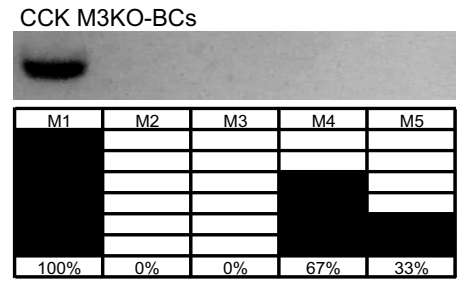

D

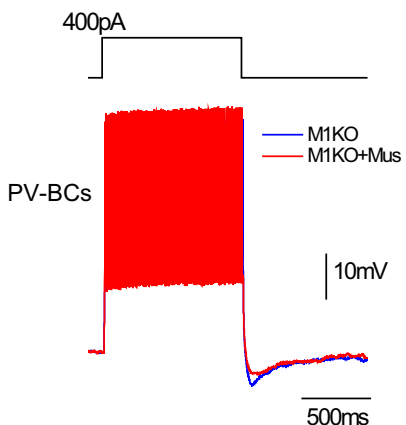

G

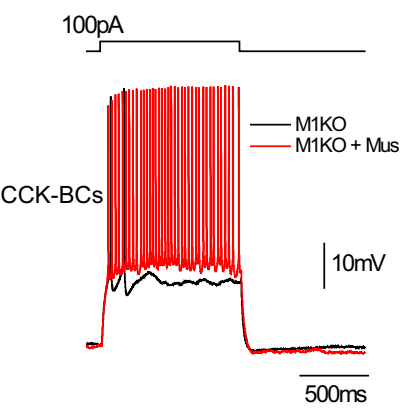

E

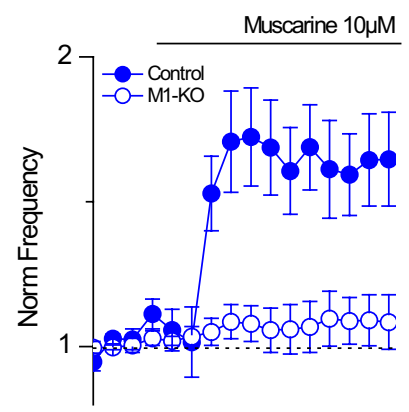

$\mathrm{H}$

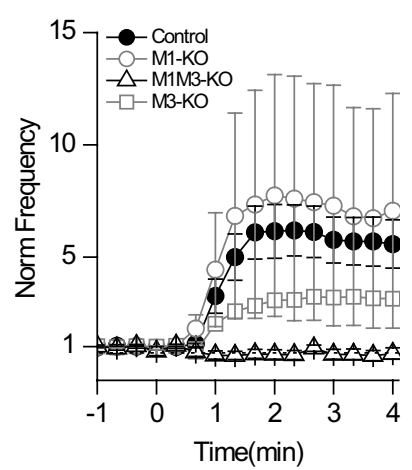

F

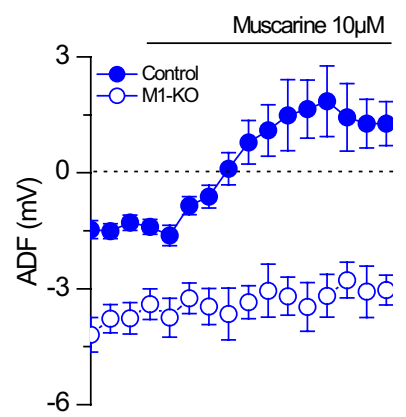

I

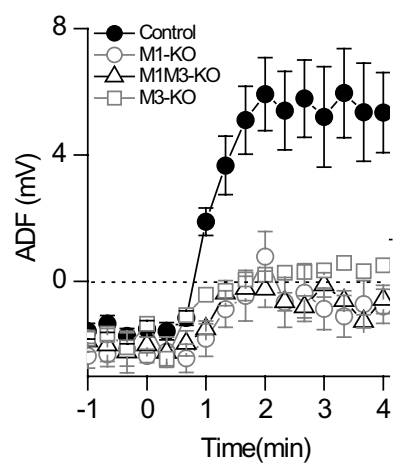

Figure 7. M3 muscarine receptor distinguishes cholinergic phenotype between PV and CCKBCS. $A-C$, Representative scRT-PCR gel and mAChR profile for PV BCs $(\boldsymbol{A})$, CCK BCs $(\boldsymbol{B})$, and M3 K0 CCK BCs (C). Each row indicates a different cell. $\boldsymbol{D}$, Representative traces for a PV BC from a M1 K0 mouse in control conditions (blue) and in the presence of $10 \mu \mathrm{m}$ muscarine (red). $\boldsymbol{E}$, Normalized AP frequency plot for WT PV BCs (blue circles) and PV BCs in M1 KO mice (open circles). $F$, ADF plot for WT PV BCS (blue circles) and PV BCs in M1KO mice (open circles). G, Representative traces for a CCK BC from a M1 KO mouse in control conditions (black) and in the presence of $10 \mu \mathrm{m}$ muscarine (red). $\boldsymbol{H}, \boldsymbol{I}$, Normalized AP frequency (H) and ADF plot (I) for WT CCK BCS (black circles), CCK BCs in M1 KO mice (open circles), CCK BCs in M3KO mice (open squares), and CCK BCs in M1/M3 double KO mice (open triangles).

of muscarine, a larger integral was seen in CCK BCs (from $-0.7 \pm 0.5$ to $22.0 \pm 6.8 \mathrm{mV}^{\star} \mathrm{s}, p=0.024$ ) than in PV BCs (from $0.7 \pm 0.8$ to $2.4 \pm 0.5 \mathrm{mV}^{\star} \mathrm{s}, p=0.1$; unpaired $t$ test $\left.p=0.046\right)$. These results indicate that $\mathrm{mAChR}$ activation fundamentally alters the way that CCK BCs respond to glutamatergic synaptic transmission.

\section{Discussion}

Two major types of BCs can be discriminated based on the selective expression of PV and CCK (Freund and Katona, 2007), which are correlated with different firing (Glickfeld and Scanziani, 2006), synaptic (Hefft and Jonas, 2005; Glickfeld and Scanziani, 2006; Daw et al., 2009), and oscillatory activities (Klausberger et al., 2005). Several studies have described PV BCs as rigid clockwork that maintains the oscillatory activity of the hippocampus, whereas CCK BCs are hypothesized to fine tune that activity by interfacing with the emotional centers of the brain (Freund and Katona, 2007). Consistent with the expression of GFP under the control of the PV promoter, we observed PV+ mRNA expression in PV-GFP fast-spiking BCs but an absence of CCK + mRNA (Fig. $1 E$ ). Conversely, CCK mRNA was expressed in all GAD65-GFP BCs, consistent with the CCK BC interneuron subtype (Fig. $1 F$ ). In combining electrophysiological, anatomical, and single cell RT-PCR approaches, we find that neurochemically distinct BC subtypes are differentially regulated by cholinergic modulation and associated with the expression of different mAChR subtypes.
Potential mechanisms underlying the distinct cholinergic phenotypes of CCK BCs and PV BCs

Using $\mathrm{mAChR}$ knock-out mice and subtype-selective antagonists, we show that CCK BCs display more robust changes in excitability in response to $\mathrm{MAChR}$ activation than PV BCs. The expression of an additional $\mathrm{mAChR}$ subtype, the M3 mAChR, accounts for this enhanced mAChR excitability in CCK BCs. We have previously shown that in oriens-lacunosum moleculare $(\mathrm{O}$ LM) neurons, M1/M3 mAChRs modulate the M-current, a slow afterpolarization current, and a cationic current (Lawrence et al., 2006a). Using mAChR KO mice, we now demonstrate that $\mathrm{mAChR}$ subtypes present on CCK BCs control distinct functional aspects of mAChR-mediated responses. M3 mAChRs primarily control firing frequency whereas both M1 and M3 mAChRs control the emergence of the mADP (Fig. 6), raising the possibility that M1 and M3 mAChRs couple to different mAChRsensitive conductances and/or are compartmentally segregated on CCK BCs. A likely candidate in muscarinic control of the firing frequency is the M-current, a potassium current mediated by Kv7 channels (Lawrence et al., 2006a,b). Consistent with M3mediated modulation of the M-current, several studies in M1 mAChR KO mice have failed to block modulation in CA1 pyramidal cells (Rouse et al., 2000; Fisahn et al., 2002). Although it is likely that both PV BCs and CCK BCs possess Kv7 channels (Cooper et al., 2001), inhibition of Kv7 channels may not influence membrane excitability to the same extent in PV BCs due to their lower relative input resistance. 
PV BCs are associated with a large M1induced increase in holding current at $-60 \mathrm{mV}$ (Fig. $3 E$ ). Given the absence of M3 mAChRs in PV BCs and evidence that M1 mAChRs are associated with a nonspecific cationic conductance in CA1 pyramidal cells (Fisahn et al., 2002) and O-LM cells (Lawrence et al., 2006a), it is possible that this same mechanism is operative in PV BCs, and to a lesser extent in CCK BCs. Therefore, if both the M- and cationic conductances are present in CCK $\mathrm{BCs}$, we predict that M1 mAChRs would couple to a cationic conductance and M3 mAChRs will inhibit the M-current.

$\mathrm{mAChR}$ activation also strongly influenced the AP waveform in CCK BCs but not in PV BCs, suggesting that the composition and expression of potassium channels mediating AP repolarization may be different in CCK BCs. Kv3.2 delayed rectifier channels likely mediate the rapid repolarization of APs in PV BCs (Atzori et al., 2000), which undergo neuromodulation through $\mathrm{H} 2$ histaminergic receptormediated inhibition (Atzori et al., 2000). However, because the AP half-width is insensitive to M1 mAChR modulation (Fig. $4 E), \mathrm{M} 1 \mathrm{mAChRs}$ and $\mathrm{H} 2$ receptors may not share common G-protein coupled signaling mechanisms. Together, it is likely that the expression of $\mathrm{mAChR}$-sensitive channels is different in PV BCs and CCK BCs.

Finally, reminiscent of observations made by McQuiston and colleagues (1999a), it was interesting in how effective glutamatergic synaptic stimulation was in exciting CCK BCs in the presence of muscarine, which seemed to provide a longer ADP than with supratheshold current steps alone. Although mAChR activation has been shown to enhance AMPA and NMDA receptor function (Markram and Segal, 1990a,b; Fernández de Sevilla et al., 2008), it is also possible that sodium and/or calcium influx through AMPA and/or NMDA receptors may amplify the excitatory postsynaptic effects of $\mathrm{mAChR}$ activation. Although there is evidence that metabotropic glutamate receptors (mGluRs) may act synergistically with mAChRs (Moore et al., 2009; Kamsler et al., 2010), mGluRla expression appears to be weak in CCK BCs (Ferraguti et al., 2004).

\section{Potential mechanisms underlying differential cholinergic transmission between CCK BCs and PV BCs}

Cholinergic neurons from the medial septum-diagonal band of Broca (MS-DBB) provide a dense innervation of the CA1 hippocampus. The innervation pattern of the cholinergic fibers is widespread (Fig. $7 A, B$ ), but synaptic stimulation of acetylcholine release onto BCs, defined morphologically but not neurochemically, has been observed in only one study to date (Widmer et al., 2006). We find that synaptic release of acetylcholine elicits larger responses in CCK BCs than in PV BCs. There are several explanations that could account for this observation. Assuming that the density and or release probability of cholinergic boutons is not different onto CCK BCs and PV BCs (Fig. $2 A, B$ ), given the presence of M3 mAChRs on CCK BCs and the more robust responses to cholinergic fiber stimulation on CCK BCs, it is possible that M3 mAChRs may be in a more privileged spatial location
B
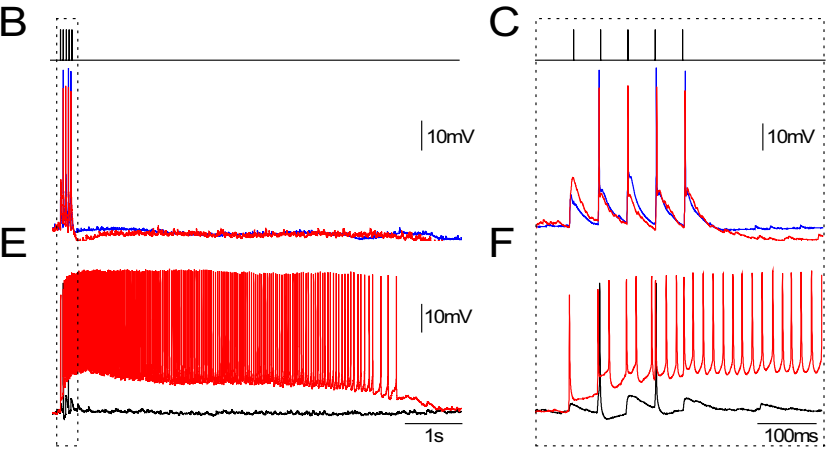

Muscarine 10 $1 \mathrm{M}$

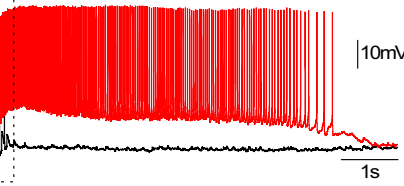

$\mathrm{H}$

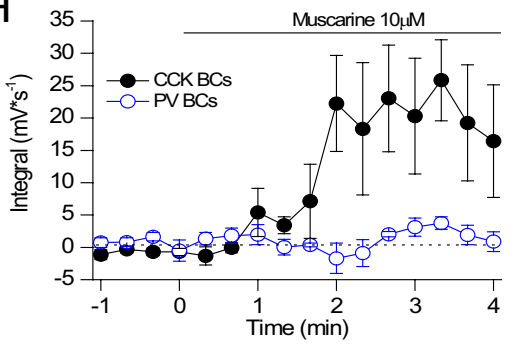

Figure 8. Glutamatergic excitation of CCK BCs is enhanced by mAChR activation. $\boldsymbol{A}, \boldsymbol{B}$, Representative trace of a single EPSP $(\boldsymbol{A})$ or a train of 5 EPSPs $(\boldsymbol{B})$ evoked onto a PV BC under control conditions (blue) or after bath application of $10 \mu \mathrm{m}$ muscarine (red).

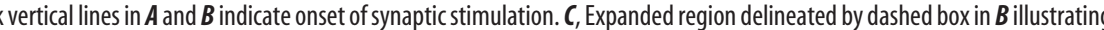
onditions. G, ADF population plot for PV BCs (black open circles) and CCK BCs (black filled circles). $\boldsymbol{H}$, Integral population plot for PV $B C s$ (black open circles) and CCK BCs (black filled circles).

for binding ACh than M1 mAChRs. Moreover, the localization of $\alpha 7 \mathrm{nAChRs}$ on CCK interneurons (Freedman et al., 1993; Morales et al., 2008) also suggests that cholinergic afferents may activate postsynaptic receptors in a manner more consistent with spatially restricted, point-to-point cholinergic transmission. Given that the acetylcholinesterase inhibitor tacrine enhances ACh release onto PV BCs, M1 mAChRs present on PV BCs may be preferentially activated via "spillover", which may occur during periods of high, sustained activity in cholinergic neurons. On the basis of this evidence, cholinergic afferents are likely to engage CCK BCs and PV BCs through different modes of cholinergic synaptic transmission.

\section{Implications for hippocampal network processing}

The hippocampus has long been known as a substrate for cognitive processes such as learning and memory (Best et al., 2001; Eichenbaum, 2004). These cognitive processes are correlated with electrical oscillations in the hippocampus (Raghavachari et al., 2001; Buzsáki, 2002), reflecting the synchronized firing of neuronal ensembles. The magnitude of these hippocampal rhythms is dynamic, a manifestation of the number and temporal synchrony of the neurons engaged. By virtue of their extensive anatomical projections to hundreds of postsynaptic targets and effectiveness of IPSPs in controlling the onset of firing of excitatory neurons (Buhl et al., 1994; Bartos et al., 2007; Freund and Katona, 2007), modulating the excitability of BCs is a potentially powerful mechanism of controlling oscillatory activity.

Having demonstrated that the activation $\mathrm{mAChRs}$ present on PV BC and CCK BC subtypes are physiologically relevant, how do the different mAChR phenotypes of PV BCs and CCK BCs contribute to inhibitory $\mathrm{BC}$ circuit function and the generation of oscillatory activity? Ablation of MS-DBB cholinergic neurons severely attenuates the magnitude of theta oscillations in the hippocampus (Lee et al., 1994). A recent study in which PV BCs were 
optically excited or silenced definitively demonstrated that activation of PV BCs themselves participate in the generation of gamma oscillations (Sohal et al., 2009). The mAChR agonist carbachol induces hippocampal gamma oscillations in vitro (Fisahn et al., 1998), raising the possibility that gamma oscillations are generated in part by cholinergic excitation of PV BCs. Interestingly, cholinergically induced gamma oscillations are abolished in M1 mAChR KO mice (Fisahn et al., 2002), as is cholinergic excitation of PV BCs (Fig. 7). Future experiments in which M1 $\mathrm{mAChRs}$ are selectively eliminated from PV BCs will shed further light on the role of PV BCs in cholinergically induced oscillatory activity.

In addition to the postsynaptic consequences of mAChR activation, presynaptic effects remain to be fully investigated. Early immunocytochemical work of Hájos et al. (1998) identified M2 mAChRs present on PV BC terminals. In contrast, $\mathrm{mAChR}$-induced inhibition of GABA release from CCK BCs occurs indirectly through postsynaptic endocannabinoid release and activation of presynaptic CB1 cannabinoid receptors (Freund and Katona, 2007; Lawrence, 2007, 2008; Neu et al., 2007). Interestingly, in addition to M2 mRNA, we also detected M4 mAChR mRNA in a subset of PV BCs and CCK BCs (Fig. 7). Therefore, to understand the full impact of cholinergic modulation on inhibitory $\mathrm{BC}$ circuits, the identity and function of presynaptic mAChRs on BC subtypes still remains to be fully clarified.

\section{Potential involvement in BCs in diseases involving cholinergic dysfunction}

A more thorough understanding of how cholinergic modulation alters the excitability of interneuron networks in the normal brain has broad implications for the study of disease processes. Alzheimer's disease is well established to involve cholinergic deficits that result in memory impairment (Coyle et al., 1983). Given the proximity of cholinergic synapses to GABAergic neurons (Fig. 2A,B), cholinergic deafferentation (Bell and Claudio Cuello, 2006) and impairment of cholinergic transmission onto hippocampal BCs will have adverse effects on the generation of oscillatory activity underlying for learning and memory functions. In addition, gamma oscillations, encoded by PV interneurons (Bartos et al., 2007; Sohal et al., 2009), are reduced in schizophrenia (Lewis et al., 2005) and may involve cholinergic dysfunction (Berman et al., 2007).

\section{Concluding Remarks}

We demonstrate that neurochemically distinct BC populations are differentially regulated by cholinergic activation of $\mathrm{mAChR}$ subtypes. This dependence on neurochemical identity signifies a unifying principle that is now shared between hippocampal and cortical interneuron fields (Madison and McQuiston, 2006; Lawrence, 2008). We anticipate that this conceptual framework will greatly facilitate the understanding of cholinergic function in hippocampal learning and memory in the coming years.

\section{References}

Ango F, Wu C, Van der Want JJ, Wu P, Schachner M, Huang ZJ (2008) Bergmann glia and the recognition molecule $\mathrm{CHL} 1$ organize GABAergic axons and direct innervation of Purkinje cell dendrites. PLoS Biol 6:e103.

Atzori M, Lau D, Tansey EP, Chow A, Ozaita A, Rudy B, McBain CJ (2000) $\mathrm{H} 2$ histamine receptor-phosphorylation of Kv3.2 modulates interneuron fast spiking. Nat Neurosci 3:791-798.

Bartos M, Vida I, Jonas P (2007) Synaptic mechanisms of synchronized gamma oscillations in inhibitory interneuron networks. Nat Rev Neurosci 8:45-56.
Bell KF, Claudio Cuello A (2006) Altered synaptic function in Alzheimer's disease. Eur J Pharmacol 545:11-21.

Berman JA, Talmage DA, Role LW (2007) Cholinergic circuits and signaling in the pathophysiology of schizophrenia. Int Rev Neurobiol 78:193-223.

Best PJ, White AM, Minai A (2001) Spatial processing in the brain: the activity of hippocampal place cells. Annu Rev Neurosci 24:459-486.

Buhl EH, Halasy K, Somogyi P (1994) Diverse sources of hippocampal unitary inhibitory postsynaptic potentials and the number of synaptic release sites. Nature 368:823-828.

Buzsáki G (2002) Theta oscillations in the hippocampus. Neuron 33:325340.

Cauli B, Audinat E, Lambolez B, Angulo MC, Ropert N, Tsuzuki K, Hestrin S, Rossier J (1997) Molecular and physiological diversity of cortical nonpyramidal cells. J Neurosci 17:3894-3906.

Cobb SR, Davies CH (2005) Cholinergic modulation of hippocampal cells and circuits. J Physiol 562:81-88.

Cobb SR, Bulters DO, Suchak S, Riedel G, Morris RG, Davies CH (1999) Activation of nicotinic acetylcholine receptors patterns network activity in the rodent hippocampus. J Physiol 518:131-140.

Cooper EC, Harrington E, Jan YN, Jan LY (2001) M channel KCNQ2 subunits are localized to key sites for control of neuronal network oscillations and synchronization in mouse brain. J Neurosci 21:9529-9540.

Coyle JT, Price DL, DeLong MR (1983) Alzheimer's disease: a disorder of cortical cholinergic innervation. Science 219:1184-1190.

Daw MI, Tricoire L, Erdelyi F, Szabo G, McBain CJ (2009) Asynchronous transmitter release from cholecystokinin-containing inhibitory interneurons is widespread and target-cell independent. J Neurosci 29: $11112-11122$.

Eichenbaum H (2004) Hippocampus: cognitive processes and neural representations that underlie declarative memory. Neuron 44:109-120.

Fernández de Sevilla D, Nuñez A, Borde M, Malinow R, Buño W (2008) Cholinergic-mediated IP3-receptor activation induces long-lasting synaptic enhancement in CA1 pyramidal neurons. J Neurosci 28:1469-1478.

Ferraguti F, Cobden P, Pollard M, Cope D, Shigemoto R, Watanabe M, Somogyi P (2004) Immunolocalization of metabotropic glutamate receptor 1alpha (mGluR1alpha) in distinct classes of interneuron in the CA1 region of the rat hippocampus. Hippocampus 14:193-215.

Fisahn A, Pike FG, Buhl EH, Paulsen O (1998) Cholinergic induction of network oscillations at $40 \mathrm{~Hz}$ in the hippocampus in vitro. Nature 394:186-189.

Fisahn A, Yamada M, Duttaroy A, Gan JW, Deng CX, McBain CJ, Wess J (2002) Muscarinic induction of hippocampal gamma oscillations requires coupling of the $\mathrm{M} 1$ receptor to two mixed cation currents. Neuron 33:615-624.

Földy C, Lee SY, Szabadics J, Neu A, Soltesz I (2007) Cell type-specific gating of perisomatic inhibition by cholecystokinin. Nat Neurosci 10:11281130.

Fortune T, Lurie DI (2009) Chronic low-level lead exposure affects the monoaminergic system in the mouse superior olivary complex. J Comp Neurol 513:542-558.

Freedman R, Wetmore C, Strömberg I, Leonard S, Olson L (1993) Alphabungarotoxin binding to hippocampal interneurons: immunocytochemical characterization and effects on growth factor expression. J Neurosci 13:1965-1975.

Freund TF, Katona I (2007) Perisomatic inhibition. Neuron 56:33-42.

Glickfeld LL, Scanziani M (2006) Distinct timing in the activity of cannabinoid-sensitive and cannabinoid-insensitive basket cells. Nat Neurosci 9:807-815.

Goldberg EM, Clark BD, Zagha E, Nahmani M, Erisir A, Rudy B (2008) K+ channels at the axon initial segment dampen near-threshold excitability of neocortical fast-spiking GABAergic interneurons. Neuron 58:387-400.

Gulyás AI, Megias M, Emri Z, Freund TF (1999) Total number and ratio of excitatory and inhibitory synapses converging onto single interneurons of different types in the CA1 area of the rat hippocampus. J Neurosci 19:10082-10097.

Hájos N, Papp EC, Acsády L, Levey AI, Freund TF (1998) Distinct interneuron types express $\mathrm{m} 2$ muscarinic receptor immunoreactivity on their dendrites or axon terminals in the hippocampus. Neuroscience 82:355-376.

Hasselmo ME (2006) The role of acetylcholine in learning and memory. Curr Opin Neurobiol 16:710-715.

Hefft S, Jonas P (2005) Asynchronous GABA release generates long-lasting 
inhibition at a hippocampal interneuron-principal neuron synapse. Nat Neurosci 8:1319-1328.

Huerta PT, Lisman JE (1993) Heightened synaptic plasticity of hippocampal CA1 neurons during a cholinergically induced rhythmic state. Nature 364:723-725.

Kamsler A, McHugh TJ, Gerber D, Huang SY, Tonegawa S (2010) Presynaptic $\mathrm{ml}$ muscarinic receptors are necessary for $\mathrm{mGluR}$ long-term depression in the hippocampus. Proc Natl Acad Sci U S A 107:1618-1623.

Klausberger T, Marton LF, O’Neill J, Huck JH, Dalezios Y, Fuentealba P, Suen WY, Papp E, Kaneko T, Watanabe M, Csicsvari J, Somogyi P (2005) Complementary roles of cholecystokinin- and parvalbumin-expressing GABAergic neurons in hippocampal network oscillations. J Neurosci 25:9782-9793.

Lambolez B, Audinat E, Bochet P, Crépel F, Rossier J (1992) AMPA receptor subunits expressed by single Purkinje cells. Neuron 9:247-258.

Lawrence JJ (2007) Homosynaptic and heterosynaptic modes of endocannabinoid action at hippocampal CCK + basket cell synapses. J Physiol 578:3-4.

Lawrence JJ (2008) Cholinergic control of GABA release: emerging parallels between neocortex and hippocampus. Trends Neurosci 31:317-327.

Lawrence JJ, Statland JM, Grinspan ZM, McBain CJ (2006a) Cell typespecific dependence of muscarinic signalling in mouse hippocampal stratum oriens interneurones. J Physiol 570:595-610.

Lawrence JJ, Saraga F, Churchill JF, Statland JM, Travis KE, Skinner FK, McBain CJ (2006b) Somatodendritic Kv7/KCNQ/M channels control interspike interval in hippocampal interneurons. J Neurosci 26:1232512338.

Ledri M, Sørensen AT, Erdelyi F, Szabo G, Kokaia M (2009) Tuning afferent synapses of hippocampal interneurons by neuropeptide Y. Hippocampus. Advance online publication. Retrieved January 1, 2010. doi:10.1002/hipo.20740.

Lee MG, Chrobak JJ, Sik A, Wiley RG, Buzsáki G (1994) Hippocampal theta activity following selective lesion of the septal cholinergic system. Neuroscience 62:1033-1047.

Lewis DA, Hashimoto T, Volk DW (2005) Cortical inhibitory neurons and schizophrenia. Nat Rev Neurosci 6:312-324.

López-Bendito G, Sturgess K, Erdélyi F, Szabó G, Molnár Z, Paulsen O (2004) Preferential origin and layer destination of GAD65-GFP cortical interneurons. Cereb Cortex 14:1122-1133.

Madison DV, McQuiston AR (2006) Toward a unified hypothesis of interneuronal modulation. J Physiol 570:435.

Mann EO, Suckling JM, Hajos N, Greenfield SA, Paulsen O (2005) Perisomatic feedback inhibition underlies cholinergically induced fast network oscillations in the rat hippocampus in vitro. Neuron 45:105-117.

Markram H, Segal M (1990a) Acetylcholine potentiates responses to $N$-methylD-aspartate in the rat hippocampus. Neurosci Lett 113:62-65.

Markram H, Segal M (1990b) Long-lasting facilitation of excitatory postsynaptic potentials in the rat hippocampus by acetylcholine. J Physiol 427:381-393.

Markram H, Toledo-Rodriguez M, Wang Y, Gupta A, Silberberg G, Wu C (2004) Interneurons of the neocortical inhibitory system. Nat Rev Neurosci 5:793-807.
McQuiston AR, Madison DV (1999a) Muscarinic receptor activity has multiple effects on the resting membrane potentials of CA1 hippocampal interneurons. J Neurosci 19:5693-5702.

McQuiston AR, Madison DV (1999b) Muscarinic receptor activity induces an afterdepolarization in a subpopulation of hippocampal CA1 interneurons. J Neurosci 19:5703-5710.

Moore SJ, Cooper DC, Spruston N (2009) Plasticity of burst firing induced by synergistic activation of metabotropic glutamate and acetylcholine receptors. Neuron 61:287-300.

Morales M, Hein K, Vogel Z (2008) Hippocampal interneurons co-express transcripts encoding the alpha7 nicotinic receptor subunit and the cannabinoid receptor 1 . Neuroscience 152:70-81.

Neu A, Földy C, Soltesz I (2007) Postsynaptic origin of CB1-dependent tonic inhibition of GABA release at cholecystokinin-positive basket cell to pyramidal cell synapses in the CA1 region of the rat hippocampus. J Physiol 578:233-247.

Parra P, Gulyás AI, Miles R (1998) How many subtypes of inhibitory cells in the hippocampus? Neuron 20:983-993.

Raghavachari S, Kahana MJ, Rizzuto DS, Caplan JB, Kirschen MP, Bourgeois B, Madsen JR, Lisman JE (2001) Gating of human theta oscillations by a working memory task. J Neurosci 21:3175-3183.

Rouse ST, Hamilton SE, Potter LT, Nathanson NM, Conn PJ (2000) Muscarinic-induced modulation of potassium conductances is unchanged in mouse hippocampal pyramidal cells that lack functional M1 receptors. Neurosci Lett 278:61-64.

Seeger T, Fedorova I, Zheng F, Miyakawa T, Koustova E, Gomeza J, Basile AS, Alzheimer C, Wess J (2004) M2 muscarinic acetylcholine receptor knock-out mice show deficits in behavioral flexibility, working memory, and hippocampal plasticity. J Neurosci 24:10117-10127.

Sohal VS, Zhang F, Yizhar O, Deisseroth K (2009) Parvalbumin neurons and gamma rhythms enhance cortical circuit performance. Nature 459:698-702.

Sun QQ, Zhang Z, Jiao Y, Zhang C, Szabó G, Erdelyi F (2009) Differential metabotropic glutamate receptor expression and modulation in two neocortical inhibitory networks. J Neurophysiol 101:2679-2692.

Toledo-Rodriguez M, Goodman P, Illic M, Wu C, Markram H (2005) Neuropeptide and calcium-binding protein gene expression profiles predict neuronal anatomical type in the juvenile rat. J Physiol 567:401-413.

Tricoire L, Pelkey KA, Daw MI, Sousa VH, Miyoshi G, Jeffries B, Cauli B, Fishell G, McBain CJ (2010) Common origins of hippocampal ivy and nitric oxide synthase expressing neurogliaform cells. J Neurosci 30:21652176.

Verbny YI, Erdélyi F, Szabó G, Banks MI (2006) Properties of a population of GABAergic cells in murine auditory cortex weakly excited by thalamic stimulation. J Neurophysiol 96:3194-3208.

Wess J, Eglen RM, Gautam D (2007) Muscarinic acetylcholine receptors: mutant mice provide new insights for drug development. Nat Rev Drug Discov 6:721-733.

Widmer H, Ferrigan L, Davies CH, Cobb SR (2006) Evoked slow muscarinic acetylcholinergic synaptic potentials in rat hippocampal interneurons. Hippocampus 16:617-628. 